\title{
Effort-related functions of nucleus accumbens dopamine and associated forebrain circuits
}

\author{
J. D. Salamone $\cdot$ M. Correa $\cdot$ A. Farrar $\cdot$ S. M. Mingote
}

Received: 17 May 2006 / Accepted: 5 December 2006 / Published online: 16 January 2007

(C) Springer-Verlag 2007

\begin{abstract}
Background Over the last several years, it has become apparent that there are critical problems with the hypothesis that brain dopamine (DA) systems, particularly in the nucleus accumbens, directly mediate the rewarding or primary motivational characteristics of natural stimuli such as food. Hypotheses related to DA function are undergoing a substantial restructuring, such that the classic emphasis on hedonia and primary reward is giving way to diverse lines of research that focus on aspects of instrumental learning, reward prediction, incentive motivation, and behavioral activation.

Objective The present review discusses dopaminergic involvement in behavioral activation and, in particular, emphasizes the effort-related functions of nucleus accumbens DA and associated forebrain circuitry.

Results The effects of accumbens DA depletions on foodseeking behavior are critically dependent upon the work requirements of the task. Lever pressing schedules that have minimal work requirements are largely unaffected by accumbens DA depletions, whereas reinforcement schedules that have high work (e.g., ratio) requirements are substantially impaired by accumbens DA depletions. Moreover, interference with accumbens DA transmission exerts a powerful influence over effort-related decision making. Rats with accumbens DA depletions reallocate their instrumental behavior away from food-reinforced tasks that have high
\end{abstract}

J. D. Salamone $(\bowtie) \cdot$ M. Correa $\cdot$ A. Farrar $\cdot$ S. M. Mingote Division of Behavioral Neuroscience, Department of Psychology, University of Connecticut,

Storrs, CT 06269-1020, USA

e-mail: john.salamone@uconn.edu

M. Correa

Àrea de Psicobiologia, Campus de Riu Sec, Universitat Jaume I, 12079 Castello, Spain response requirements, and instead, these rats select a lesseffortful type of food-seeking behavior.

Conclusions Along with prefrontal cortex and the amygdala, nucleus accumbens is a component of the brain circuitry regulating effort-related functions. Studies of the brain systems regulating effort-based processes may have implications for understanding drug abuse, as well as energyrelated disorders such as psychomotor slowing, fatigue, or anergia in depression.

Keywords Reward - Motivation - Effort anergia .

Depression · Conditioning · Drug abuse

\section{Moving beyond the DA hypothesis of reward}

Brain dopamine (DA) systems have been implicated in a number of neurological and psychiatric disorders, including Parkinson's disease, schizophrenia, depression, and drug addiction, and have been hypothesized to play an important role in cognition, motivation, and movement control. But among all the hypothesized functions of mesolimbic DA, perhaps the most widely cited one is that DA mediates "reward" processes. For the better part of three decades, it has been suggested that DA systems in the brain, particularly in nucleus accumbens, directly mediate the rewarding or primary motivational characteristics of natural stimuli such as food, water, and sex. In turn, it has been argued that this so-called "natural reward system" is activated by drugs of abuse, and that this activation is a critical factor involved in the development of drug reward, and ultimately, addiction. Within the last few years, it has become evident that there are numerous problems with the general form of the DA-reward hypothesis (Salamone et al. 1997, 2003, 2005, 2006; Kelley et al. 2005; Everitt and 
Robbins 2005; Robbins and Everitt 2007). Indeed, even the proponents of this hypothesis have engaged in dramatic revisions of its content. For example, although the original hypothesis (e.g., Wise et al. 1978a,b; Wise 1982) emphasized the role that pleasure played in mediating the effects of dopaminergic manipulations (hence the use of the term "anhedonia"), it is becoming more common to place greater emphasis on DA as regulating learning processes related to reinforcement (e.g., Wise 2004). Nevertheless, the idea that DA mediates pleasure has been seized upon by textbook authors, the popular press, filmmakers, and the internet, all of which has elevated DA from its hypothesized involvement in reward to an almost mythological status as a "pleasure chemical" mediating not only euphoria and addiction, but also "love". Yet despite the popular embrace of DA as a pleasure chemical (e.g., Peterson 2005), the actual science is far more complicated. In fact, it has been argued that this area is currently undergoing something reminiscent of a Kuhnian "paradigm shift" (Salamone 2007; see Kuhn 1962 for discussion of paradigm shifts in science), such that the classic emphasis on hedonia and primary reward is yielding to diverse lines of research that focuses on aspects of instrumental learning, pavlovian/ instrumental interactions, reward prediction, incentive salience, and behavioral activation.

The present paper will review some of the difficulties with the DA hypothesis of reward, will briefly present some of the alternative hypotheses, and will emphasize the involvement of nucleus accumbens DA in behavioral activation and effort-related processes. Of course, accumbens DA does not regulate effort-related functions in isolation and the discussion below will include other structures such as prefrontal cortex, amygdala, and ventral pallidum. Studies of the brain systems regulating effortrelated processes have become more common in recent years (e.g., Salamone et al. 2003; Rushworth et al. 2004; Walton et al. 2006; Phillips et al. 2007), not only because of the basic scientific importance of understanding activational aspects of motivation, but also because of its potential clinical relevance. This area of research may have implications for understanding phenomena related to natural motivation, drug abuse, and energy-related disorders such as psychomotor slowing, fatigue, or anergia in depression (Salamone et al. 2006).

\section{The DA hypothesis of reward: what is "reward"?}

Although the terms "reinforcement" and "reward" are sometimes used interchangeably, they also can convey different meanings. The term reinforcement has been used for years in many different contexts (e.g., engineering, military) and generally refers to a process of "strengthen- ing". Although a Russian form of the word "reinforcement" was used by Pavlov in reference to aspects of classical conditioning, the origin of the modern behavioral term and its widespread usage in relation to instrumental conditioning is more associated with Skinner (Dinsmoor 2004). Reinforcement refers to behavioral contingencies that act to strengthen a particular behavior. More specifically, positive reinforcement refers to a process by which a response is followed by the presentation of stimulus that typically is contingent upon that response; these events are followed by an increase in the probability of the occurrence of that response in the future. When used in the Skinnerian sense, the term reinforcement has no specific emotional or motivational meaning. Rather, it refers to a set of conditions that lead to changes in response probability or frequency. Reinforcers also have been said to "stamp-in" the responses with which they are associated, which is a fundamental component of reinforcement that is related to learning. Furthermore, reinforcers can act to maintain performance of responses that have already been learned. Although Skinner himself did not discuss the relation between reinforcement and motivation in detail, researchers who have considered the characteristics of stimuli that enable them to act as reinforcers have generally come to emphasize that reinforcers have motivational properties (Salamone and Correa 2002). Thorndike, Hull, Spence, Premack, Timberlake, and Dickinson, despite their different perspectives, all have emphasized that there is a fundamental motivational component to reinforcement processes (Dickinson and Balleine 1994; Salamone and Correa 2002). A positive reinforcer can be described as a goal or, in economic terms, a commodity. Reinforcers are stimuli that are approached, selfadministered, attained, or preserved in some way; they are activities that are relatively preferred or deprived compared to baseline level. This fundamental motivational characteristic of reinforcing stimuli is sometimes referred to as the primary or "unconditioned" reinforcing property of those stimuli (Nader et al. 1997; Stefurak and van der Kooy 1994).

Despite the fact that "reward" can be used as a synonym for "positive reinforcer" when it refers to a stimulus, or "positive reinforcement" when it refers to a process, the term "reward" also has many additional connotations (see Cannon and Bseikri 2004), the most common of which deal with emotion and motivation (White 1989; Stellar 2001; Everitt and Robbins 2005). Thus, the use of the term reward can provide emphasis that positive reinforcers have emotional effects (e.g., "subjective, attributional aspects", Everitt and Robbins 2005), such as feelings of pleasure. In addition, reward can refer to the observation outlined above that positive reinforcers also have appetitive motivational characteristics (White 1989). Early papers describing the DA hypothesis of reward emphasized these characteristics in suggesting that interference with DA transmission 
produced "anhedonia" or appetitive motivational impairments (Wise 1982, 1985; Wise et al. 1978a). Consistent with this conceptualization of reward as based upon primary or unconditioned motivation, researchers have employed measures of consummatory behavior to study the hypothesized effects of DA antagonists on "reward", including food intake (Wise and Colle 1984; Wise and Raptis 1985) and sucrose intake (Xenakis and Sclafani 1982; Muscat and Willner 1989; Yu et al. 2000; see reviews by Smith 1995, 2004). In discussing the hypothesized reward functions of DA, many researchers have focused upon emotional or hedonic aspects of motivation. Such ideas have been particularly popular in the drug abuse and self-administration literatures (e.g., Gardner 1992, 2005).

In summary, many researchers have emphasized the idea that interference with DA transmission produces anhedonia and impairs the primary motivational characteristics of positive reinforcers. This perspective has been referred to as the "General Anhedonia Model" (Salamone et al. 1997; Salamone and Correa 2002). Moreover, terms such as "reward" and "anhedonia" were used to convey a sense of the hypothesized emotional and motivational impact of interference with DA transmission. In view of these observations, it is useful to review the literature related to the concept that interference with DA transmission impairs the pleasurable or primary motivational impact of natural reinforcers such as food.

\section{Empirical and conceptual problems with the DA hypothesis of reward: reward as pleasure}

Despite its popularity, the idea that interference with DA systems causes "anhedonia" is highly controversial. For example, studies of taste reactivity to food in animals have been problematic for the general anhedonia model. Considerable research with the taste reactivity paradigm has demonstrated that interference with DA by systemic administration of DA antagonists, whole forebrain DA depletions, or local depletions of DA in nucleus accumbens or neostriatum, failed to alter appetitive taste reactivity for sucrose (Berridge et al. 1989; Berridge 2000; Berridge and Robinson 1998; Treit and Berridge 1990). This has led Berridge et al. to conclude that brain DA does not mediate "liking" (i.e., the hedonic reaction to food). Nevertheless, these authors have suggested that DA systems are involved in "wanting" of natural and drug rewards (see Berridge 2007).

The involvement of DA systems in aspects of motivated behavior is not limited to appetitive motivation or conditions involving pleasure. Considerable evidence has illustrated that DA systems also are involved in functions related to aversive motivation (McCullough et al. 1993a,b; Salamone 1994; Salamone et al. 1997; Killcross et al. 1997;
Di Chiara 2002; Huang and Hsiao 2002). Although it is sometimes stated that increases in DA release are only associated with appetitive stimuli but not aversive ones (e.g., Burgdorf and Panksepp 2006), this contention is not supported by the literature. Neurochemical measures of accumbens DA transmission are elevated in response to aversive conditions as diverse as footshock, tailshock, tailpinch, restraint stress, instrumental avoidance, conditioned aversive stimuli, anxiogenic drugs, and social stress (Salamone 1994, 1996; McCullough et al. 1993a,b; Tidey and Miczek 1996; Salamone et al. 1997; Datla et al. 2002; Young 2004; Marinelli et al. 2005). Although the time resolution of microdialysis methods makes it difficult to establish specific relations between neurochemical changes and transient environmental or behavioral events, several investigators have used electrophysiological and voltammetric methods to obtain sub-second markers of phasic DA activity. Researchers continue to debate the significance of these phasic DA signals and how they are related to reward prediction, novelty, reinforcer-seeking, or other functions (Horvitz 2000; Schultz 2002; Ungless 2004; Roitman et al. 2004; Salamone et al. 2005; Lavin et al. 2005; Redgrave and Gurney 2006; Lapish et al. 2007). Nevertheless, electrophysiology studies in awake animals have shown that putative ventral tegmental DA neurons show increased activity in response to conditioned aversive stimuli (Guarraci and Kapp 1999) and restraint stress (Anstrom and Woodward 2005).

In humans, the role of DA as a mediator of pleasure remains uncertain (Barrett 2006). Parkinson's disease was not found to be associated with alterations in the perceived pleasantness of taste stimuli (Sienkiewicz-Jarosz et al. 2005). Although Gunne et al. (1972) reported that the euphoric effects of amphetamine could be blocked by DA antagonism, subsequent research has challenged this notion. Gawin (1986) described cocaine users who received DA antagonists; these patients actually reported continued euphoria from cocaine and lengthened cocaine binges. Brauer and De Wit (1997) reported that pimozide failed to blunt amphetamine-stimulated euphoria. Wachtel et al. (2002) observed that neither the typical antipsychotic haloperidol nor the atypical antipsychotic risperidone suppressed the positive subjective effects of methamphetamine. The D1 antagonist ecopipam failed to blunt the selfadministration and subjective euphoria that were induced by cocaine (Haney et al. 2001; Nann-Vernotica et al. 2001). Thus, there is not a clear set of findings indicating that antagonism of DA receptors blocks drug-induced euphoria or "high" (Wachtel et al. 2002). Furthermore, a recent study demonstrated that catecholamine depletion induced by feeding people a phenylalanine/tyrosine-free diet did not reduce cocaine-induced euphoria or self-administration (Leyton et al. 2005). One also can question the importance 
of pleasure as a critical mediator of drug abuse (Wachtel et al. 2002; Correa and Salamone 2006). Additional factors, including strength of engagement, also appear to affect reinforcement value (Higgins 2006).

Imaging methods have allowed for the in vivo assessment of structure and activity in DA terminal areas in humans. Several studies have focused upon emotional stimuli; as was the case with the early animal literature, a common view has become that accumbens activity as measured in imaging studies is closely associated with pleasure (e.g., Peterson 2005; Keedwell et al. 2005; Sarchiapone et al. 2006). However, within the last few years, it has become apparent that nucleus accumbens in humans is related to a diverse array of emotional and motivational stimuli (Barrett 2006). Burgdorf and Panksepp (2006) suggested that ventral striatal mechanisms are not related to "pleasure" or "consummatory reward" in the traditional sense, but instead are related to anticipatory or appetitive energizing effects of stimuli. Knutson et al. (2001, 2003) reported that accumbens fMRI activation was evident in people performing a gambling task, but that the increased activity was associated with reward prediction or anticipation rather than presentation of the monetary reward per se. O'Doherty et al. (2002) observed that anticipation of glucose delivery was associated with increased fMRI activation in midbrain and striatal DA areas, but that these areas did not respond to glucose delivery. Anticipation of an aversive cutaneous stimulus also was reported to be associated with fMRI activation of ventral striatum (Jensen et al. 2003). Activation of accumbens fMRI responses was related to emotional intensity for both positive and aversive conditions (Phan et al. 2004). Vietnam veterans with post-traumatic stress disorder showed increased blood flow in the accumbens in response to the presentation of aversive stimuli (i.e., combat sounds; Liberzon et al. 1999). Aharon et al. (2006) observed that distinct subregions of the accumbens undergo temporally dependent activation or inhibition of fMRI signals in response to a painful thermal stimulus, which could be related to the perception or anticipation of the stressor. Although most imaging studies do not deal directly with DA per se, a recent study used PET measurements of in vivo raclopride displacement to assess DA release in humans and observed that exposure to psychosocial stress increased markers of extracellular DA in the ventral striatum in a manner that was correlated with increased cortisol release (Pruessner et al. 2004).

\section{Empirical and conceptual problems with the DA hypothesis of reward: reward as primary appetitive motivation for natural stimuli}

In addition to these problems with the hypothesis that DA mediates the pleasurable impact of rewards, there also are substantial difficulties with the notion that accumbens DA mediates unconditioned reinforcement or primary motivation for natural stimuli such as food (Salamone et al. 1997; Salamone and Correa 2002). Evidence indicating that accumbens DA is important for drug self-administration (e.g., Roberts et al. 1977; Caine and Koob 1994; Chevrette et al. 2002) does not provide direct support for the hypothesis that this system mediates the primary motivational effects of natural stimuli. The mesolimbic dopamine system is thought to promote behavioral activation, arousal, attention, conditioning, and other functions, and the drugrelated induction of these effects could lead to selfadministration but that does not necessarily mean that the primary function of the system in relation to natural stimuli is "reward" (Salamone et al. 2005; Everitt and Robbins 2005; Robbins and Everitt 2007). Indeed, activities such as wheel running, exploration, and other forms of stimulation can be reinforcing but involvement of DA in regulating these activities, or others such as lever pressing, does not demonstrate that DA mediates the rewarding impact of food per se (Salamone et al. 1997). In fact, the hypothesized involvement of accumbens DA in the primary motivating effects of natural stimuli such as food (e.g., appetite for food) is one of the keys to the general form of the DA reward hypothesis (Salamone and Correa 2002) because it is supposedly the DA-mediated natural "reward system" that is being activated by drugs of abuse.

If low doses of DA antagonists suppress lever pressing for food because they produce a broad or general reduction in food motivation, then it is reasonable to suggest that behavioral markers of diminished appetite or alterations of perceived reward magnitude should be evident in the same dose range as the suppression of lever pressing. In fact, DA antagonists generally impair lever pressing for food at doses lower than those that suppress food intake or simple approach responses for food (Fibiger et al. 1976; Rolls et al. 1974; Rusk and Cooper 1994; Salamone 1986). Similar effects have been reported for water reinforcement as well (Horvitz et al. 1993; Ljungberg 1987, 1988, 1990). Low doses of D2 antagonists such as haloperidol, which substantially decrease lever pressing, actually tend to increase meal size (Clifton 2000). Furthermore, several reports indicate that doses of DA antagonists that impaired response rate measures of behavior did not alter response choice measures (Bowers et al. 1985; Cousins et al. 1996; Evenden and Robbins 1983; Salamone 1986; Salamone et al. 1994). Systemic injections of haloperidol at doses that altered response bias or effort-related choice did not impair discrimination of reinforcement density (Salamone et al. 1994; Aparicio 2003a,b). Instrumental responses with very low response requirements are extremely resistant to moderate/high doses of DA antagonists (Ettenberg et al. 1981; Salamone 1986), which demonstrates that the 
capacity to reinforce some types of instrumental behavior is left intact despite severe impairments in lever pressing at these same doses. Martin-Iverson et al. (1987) measured operant responses in a psychophysical procedure and reported that haloperidol did not reduce perceived reinforcement magnitude. Together with the evidence indicating that fundamental aspects of food motivation are left intact after interference with accumbens DA transmission (e.g., Kelley et al. 2005; Salamone and Correa 2002), these data indicate that it is difficult to attribute the suppression of lever pressing induced by low doses of DA antagonists or accumbens DA depletions to changes in primary food motivation or appetite (Salamone and Correa 2002; Kelley et al. 2005). Rather, these manipulations appear to dissociate aspects of primary food motivation from features of instrumental responding for food ${ }^{1}$, leaving appetite basically intact but instead impairing aspects of instrumental behavior such as response rate or speed (Salamone and Correa 2002; Kelley et al. 2005).

DA antagonists suppress sucrose intake, which has been suggested to provide support for the DA hypothesis of reward (Smith 1995, 2004). Nevertheless, there are several problems with this idea (Salamone and Correa 2002). Although the frequency of tongue movements is only marginally affected by DA antagonists, neuroleptic-induced deficits in sucrose intake are accompanied by several other oral motor impairments (i.e., changes in lick duration, force and efficiency, lap volume, and tongue extension; Fowler and Mortell 1992; Das and Fowler 1996). Effects on sucrose drinking produced by DA antagonists have been viewed as indicating a reduced effort for obtaining the sucrose (Hsiao and Chen 1995) and as a lack of sensorimotor responsiveness (Muscat and Willner 1989). Although feeding is impaired by higher doses of DA antagonists, there is little evidence that this reflects a loss of appetite, and considerable evidence indicates that these deficits are related to motor dysfunctions (Salamone et al. 1990; Salamone and Correa 2002). The suppression of food intake induced by high doses of DA antagonists is accompanied by a substantial decrease in rate or efficiency of feeding (Blundell 1987; Salamone et al. 1990; Clifton et al. 1991; Clifton 2000), whereas other drugs that are thought to affect appetite or food aversion, such as CB1 antagonists, suppressed food intake but did not reduce feeding rate (McLaughlin et al. 2005).

\footnotetext{
${ }^{1}$ Several authors have made distinctions between aspects of motivated behavior that are dissociated by dopaminergic manipulations (e.g., activational vs directional, Salamone 1988; preparatory vs consummatory, Blackburn et al. 1989; instrumental vs consummatory, Salamone 1991; anticipatory vs consummatory, Ikemoto and Panksepp 1996; Burgdorf and Panksepp 2006; ethanol seeking vs ethanol intake, Czakowski et al. 2002; anticipatory vs hedonic, Barbano and Cador 2007).
}

Accumbens DA depletions induced by local injections of 6-hydroxydopamine (6-OHDA) have been shown not to suppress 24-h food intake (Koob et al. 1978; Salamone et al. 1993a; Ungerstedt 1971) and failed to affect parameters such as food handling, rate of feeding, or total time spent feeding (Salamone et al. 1993a). Because time allocation has been viewed as a critical behavioral marker of reinforcement value (Baum and Rachlin 1969), these results suggest that accumbens DA depletions do not blunt food reinforcement. Intra-accumbens injections of DA antagonists at doses that impair locomotion and run speed were shown not to affect feeding or sucrose intake (Bakshi and Kelley 1991; Ikemoto and Panksepp 1996; Baldo et al. 2002). Although forebrain DA depletion severely impairs feeding (Salamone et al. 1990), considerable evidence indicates that this effect is not dependent upon DA depletions in nucleus accumbens (Koob et al. 1978; Salamone et al. 1993a). Instead, suppression of feeding is produced by interference with DA transmission in neostriatum (Dunnett and Iversen 1982; Jicha and Salamone 1991; Salamone et al. 1993a; Sotak et al. 2005) and, in particular, the lateral or ventrolateral subregion of striatum (Dunnett and Iversen 1982; Jicha and Salamone 1991; Salamone et al. 1993a; see also Pisa and Schranz 1988). These deficits in feeding are related to orofacial and forepaw motor deficits and reductions in feeding rate that result from DA depletions in this region (Jicha and Salamone 1991; Salamone et al. 1993a).

Although it was originally suggested that the effects of interference with DA transmission resembled those of extinction, several studies have failed to support this hypothesis (Salamone 1986, 1988; McCullough et al. 1993a; Salamone et al. 1995, 1997; Salamone and Correa 2002; Rick et al. 2006). Furthermore, the effects of DA antagonists and DA depletions differ substantially from the effects of motivational manipulations such as pre-feeding to reduce food motivation and administration of appetite suppressant drugs. Salamone et al. (1990) reported that the interference with DA transmission produced effects on feeding rate and time spent feeding that were distinct from the effects of pre-feeding. Using a concurrent lever pressing/chow-feeding choice task (see details below), DA antagonists and accumbens DA depletions have generally produced effects that were different from those produced by appetite suppressants and pre-feeding to reduce food motivation (Salamone et al. 1991, 1997; Salamone and Correa 2002; Cousins et al. 1993; Sokolowski and Salamone 1998; Koch et al. 2000; Nowend et al. 2001). Although depletions of accumbens DA can interfere with instrumental behavior under some conditions, considerable evidence indicates a relative sparing of performance on some schedules of food reinforcement, including variable ratio 2.5 (Roberts et al. 1977), fixed-interval (FI) $30 \mathrm{~s}$ 
(Cousins et al. 1999), and variable-interval (VI) 30, 60 or 120 s schedules (Sokolowski and Salamone 1998; Correa et al. 2002; Mingote et al. 2005). Food-reinforced FR1 performance is relatively insensitive to the effects of accumbens DA depletions (McCullough et al. 1993b; Salamone et al. 1995; Aberman and Salamone 1999; Ishiwari et al. 2004). The fact that positively reinforced behavior on some schedules is not impaired by accumbens DA depletion, or is affected only slightly, suggests that maintenance of positively reinforced responding per se is not the key process that is impaired by these depletions. The FR 1 schedule is highly sensitive to extinction and to reinforcer devaluations such as pre-feeding (Aberman and Salamone 1999; Salamone et al. 1995); yet, this schedule is relatively insensitive to accumbens DA depletions. Thus, fundamental aspects of primary food reward remain intact after depletions of accumbens DA. Although the present review is focused upon the role of DA in food motivation, similar conclusions have been reached in studies involving sexual behavior (Hull et al. 1991; Paredes and Agmo 2004) and maternal behavior (Numan et al. 2005; Pereira et al. 2005).

\section{Moving beyond the reward hypothesis: mesolimbic DA, reinforcement-related processes, and instrumental learning}

It has become evident that there are numerous problems with the general form of the DA-reward hypothesis (Salamone et al. 1997, 2003, 2005, 2006; Kelley et al. 2005). In fact, one of the ironies in this area has been that the aspects of reinforcement that are most directly conveyed by the use of the term "reward" (i.e., pleasure or primary appetitive motivation) are the very aspects of motivated behavior that are most preserved after interference with DA transmission. For these reasons, and many others, this area is currently undergoing a conceptual restructuring. The traditional emphasis on dopaminergic involvement in hedonia and primary reward is diminishing, as researchers consider the diverse array of functions regulated by nucleus accumbens (Wise 2004; Everitt and Robbins 2005; Kelley et al. 2005; Salamone et al. 2005; Berridge 2007). Although the focus of the present review is on the involvement of DA in behavioral activation and effort, it is useful to place these functions of DA into a theoretical context by briefly reviewing the broader literature on the involvement of DA in other processes related to reinforcement, such as instrumental learning. Some researchers have come to deemphasize the role of pleasure as a substrate for the action of DA and have instead come to emphasize dopaminergic involvement in instrumental learning processes related to reinforcement (e.g., Wise 2004). This reflects a recent trend in the literature, in which researchers focus upon the involvement of DA in learning processes related to the acquisition of positively reinforced behavior (e.g., SmithRoe and Kelley 2000; Kelley 2004; Kelley et al. 2005; Wise 2004; Choi et al. 2005). A thorough review of this area is beyond the scope of the present paper, and there continue to be disagreements about the specific mechanisms underlying the effects of dopaminergic manipulations on learning processes (e.g., Kelley et al. 2005; Wise 2004; Robinson et al. 2005; Cagniard et al. 2006; Ahn and Phillips 2007; Phillips et al. 2007; Berridge 2007). Nevertheless, a few points need to be emphasized in the context of the present paper. First of all, it is important to recognize the distinction between studies of the involvement of DA in learning and the traditional DA hypothesis of reward. The idea that DA is involved in aspects of instrumental learning is quite distinct from the hypothesis that DA mediates the pleasurable or the primary motivational properties of natural stimuli such as food (Salamone and Correa 2002; Salamone et al. 2005; Everitt and Robbins 2005). This point has been highlighted in the work of Kelley (e.g., Smith-Roe and Kelley 2000, 2004; Kelley et al. 2005). Thus, the general hypothesis that DA systems are involved in learning, or even the more specific hypothesis that they are involved in the "stamping-in" processes that underlie reinforcement acquisition, is not a mere extensions of the DA hypothesis of "reward". These are different hypotheses altogether and should be recognized as such.

An additional line of research in this area has focused upon the role of neostriatal mechanisms in learning. Striatal neurons show long-term changes in activity that can be correlated with changes in behavioral performance seen during procedural learning (Barnes et al. 2005). Activity patterns of striatal neurons were modified during the course of stimulus-response learning, and it has been suggested that the neostriatum acts to "chunk" the representations of motor and cognitive processes so that they can be executed as units (Graybiel 1998). Depletions of DA with MPTP impaired the ability to initially learn sequences of movements and implement them as single motor programs (Matsumoto et al. 1999). Yet despite these studies demonstrating the involvement of neostriatal mechanisms in aspects of learning, it should be emphasized that they do not provide support for the idea that these striatal mechanisms are related specifically to the hedonic or motivational impact of positive reinforcers on behavior. For example, tonically active striatal neurons are activated during aversive learning as well as reward-related learning (Blazquez et al. 2002). In addition, studies involving different types of memory procedures indicate that interference with striatal function does not uniformly affect all forms of reward-based learning. Inactivation of neostriatum impaired acquisition on a response learning task but, unlike 
hippocampal inactivation, did not impair the acquisition of the spatial working memory task (Packard and McGaugh 1996). Nevertheless, both forms of learning in this study involved positive reinforcement. Thus, it seems clear that the specific aspect of learning being disrupted by striatal inactivation in these experiments was not the impact of a positive reinforcer, per se.

Another important point is related to the selectivity involved in the use of the term "reinforcement" in relation to learning studies. The involvement of DA in instrumental learning is not unique to procedures involving positive reinforcement. An enormous literature, stretching back several decades, details the involvement of DA systems in the acquisition of tasks involving aversive motivation (Salamone 1994; Santi and Parker 2001; Di Chiara 2002; Huang and Hsiao 2002; Pezze and Feldon 2004; Li et al. 2004). This involvement relates not only to negatively reinforced behavior, which is characterized by increases in response probability, but also to procedures such as place aversion, taste aversion, and passive avoidance, in which behavior is suppressed by punishment. Moreover, nucleus accumbens lesions have been shown to disrupt learning about aversive outcomes (Schoenbaum and Setlow 2003). Thus, the involvement of DA or striatal mechanisms in learning processes is not strictly limited to situations involving positive reinforcement. If researchers wish to refer to the hypothesis that DA systems are involved in aspects of learning, it seems as though the term "reinforcement" only captures part of the story. The term "instrumental learning" may be preferable, partly because it captures better the breadth of processes involved (that is, it includes positive reinforcement, negative reinforcement, and punishment), and also because it would do so without evoking misleading notions about dopaminergic involvement in "reward".

Finally, it should be stressed that the hypothesized involvement of mesolimbic DA in aspects of instrumental learning is not incompatible with the literature demonstrating that this system is involved in behavioral activation and effort-related processes (Kelley et al. 2005). It is doubtful that accumbens DA performs only one function, and evidence in favor of the hypothesis that DA is involved in learning does not constitute evidence against the hypothesis that DA is involved in behavioral activation.

\section{Behavioral activation functions of nucleus accumbens DA: an overview}

Motivation is a term that refers to the behaviorally relevant processes that enable organisms to regulate their external and internal environment. Organisms behave in such a way as to regulate the proximity or probability of wide array of stimuli. Behavior is directed towards or away from particular stimuli, as well as activities that involve interacting with those stimuli; organisms seek some conditions and avoid others, both in active and passive ways. In addition to these "directional" aspects of motivation, it has been recognized for many years that there are "activational" aspects as well (Duffy 1963; Cofer and Appley 1964; Salamone 1988). Motivated behavior is characterized by vigor, persistence, and high levels of work output. The concepts of "drive" and "incentive" offered by Hull et al. (1991) and Spence (1956) emphasized that motivational conditions can produce energizing effects on behavior. Researchers who conducted early studies of the neural basis of motivation and emotion emphasized the role that arousal and "energy mobilization" played in these processes (e.g., Lindsley 1951; Moruzzi and Magoun 1949; Rubio-Chevannier et al. 1961). Cofer and Appley (1964) posited the existence of an "anticipation-invigoration mechanism," which was activated by conditioned stimuli and served to invigorate instrumental behavior. Collier and Jennings (1969) emphasized how work requirements of a task are an important determinant of instrumental behavior, an idea that is consistent with "economic models" of operant conditioning (Lea 1978; Hursh et al. 1988; Bickel et al. 2000). Similar concepts also have been offered in the ethnology literature. Animals foraging in the wild exert considerable energy to obtain food or water, and optimal foraging theory was proposed to account for the fact that the amount of effort or time expended to obtain these stimuli was an important determinant of behavioral choice (Krebs 1977). Psychologists and psychiatrists also have discussed the importance of behavioral activation processes for various clinical syndromes. Psychomotor slowing, anergia, and fatigue are important features of depression and also can be associated with a variety of other psychiatric or neurological conditions (Salamone et al. 2006).

For many years, the terms "arousal" and "activation" were used to refer to a collection of processes that are now viewed as distinct in terms of their mechanisms. Thus, researchers in the 1950s-1960s generally grouped together cortical activation as measured by the electroencephalograph, sympathoadrenal activation, and the invigoration or activation of motivated behavior, under umbrella terms such as degree of excitation, energy mobilization, activation, and arousal (e.g., Bartoshuk 1971, p 831). As research on each of these functions became more specialized, it became evident that different physiological mechanisms were involved in each distinct dimension of arousal, and indeed the concept of "general arousal" began to slowly disappear. Nevertheless, the concept of "behavioral arousal" or "behavioral activation", and its neural basis, became an important feature of behavioral neuroscience research in the 1970s-1980s. Much of the attention in this era focused 
upon the role that forebrain DA systems played in behavioral activation. Although several studies have implicated neostriatal DA in behavioral activation (e.g., Neill and Herndon 1978), the present review is focused upon the role of nucleus accumbens DA in behavioral activation and effort-related processes. One of the most frequently used procedures for studying behavioral activation in rats is locomotor activity. This response, readily measured in rodents, has been used for decades to provide both an index of a specific aspect of motor function as well as a measure of behavioral activation that is related to motivation. Increased locomotor activity is one of the hallmarks of psychomotor stimulants, and considerable attention has focused upon the role that accumbens DA plays in mediating the locomotor stimulant effects of such drugs. The locomotion induced by low doses of amphetamine was suppressed by intra-accumbens injections of haloperidol (Pijnenburg et al. 1975) and by accumbens DA depletions (Kelly et al. 1975). Microinjections of stimulants into the nucleus accumbens increased locomotor activity (Delfs et al. 1990). Nucleus accumbens DA also is involved in sensorimotor gating functions related to behavioral activation (Swerdlow et al. 1990; Koob and Swerdlow 1988).

Exposing animals to scheduled non-contingent presentation of reinforcers such as food can induce various activities, including locomotion, drinking, licking, and wheel-running (Falk 1971; Staddon and Simmelhag 1971; Killeen 1975; Killeen et al. 1978; Lopez-Crespo et al. 2004). Considerable evidence indicates that mesolimbic DA is involved in schedule-induced activity. Accumbens DA depletions impair a variety of schedule-induced activities, including drinking (Robbins and Koob 1980; Wallace et al. 1983; Robbins et al. 1983; Mittleman et al. 1990) and wheel-running (Wallace et al. 1983). Scheduleinduced locomotion was blocked by haloperidol (Salamone 1988) and accumbens DA depletions (McCullough and Salamone 1992). Schedule-induced behavior is accompanied by increases in accumbens DA release as measured by microdialysis (McCullough and Salamone 1992) and voltammetry (Weissenborn et al. 1996). Together with studies on dopaminergic involvement in stimulant-induced and spontaneous locomotion, studies of schedule-induced behavior provide critical support for the idea that accumbens DA is an important part of the brain circuitry involved in behavioral activation. This is consistent with the idea that the accumbens serves as an interface between limbic system areas involved in emotion and motivation and components of the motor system that regulate behavioral output (Mogenson et al. 1980).

The notion that forebrain DA systems are involved in behavioral activation has received widespread support from a broad range of investigators (Robbins and Everitt 2007). Moreover, several studies providing support for the hypothesis that accumbens DA is involved in behavioral activation also have yielded evidence against the hypothesis that accumbens DA mediates primary food motivation. Accumbens DA depletions that impaired spontaneous locomotion failed to suppress food intake (Koob et al. 1978). Systemic haloperidol administration severely impaired schedule-induced locomotor activity, yet did not disrupt the food-reinforced behavior of simply being in a particular location on a FI schedule (Salamone 1986). D1 and D2 antagonists injected into either core or shell subregions of accumbens suppressed locomotor activity but did not impair food intake (Baldo et al. 2002). These studies demonstrate that the effects of dopaminergic manipulations on indices of behavioral activation in foodrelated tasks are not simply dependent upon changes in primary food motivation or appetite. Instead, the preponderance of evidence suggests that these experiments serve to dissociate dopaminergic involvement in behavioral activation from processes mediating primary food motivation or appetite (Salamone 1988, 1992; Salamone et al. 1997, 2003; Kelley et al. 2005).

\section{Nucleus accumbens DA and the exertion of effort}

As noted above, interference with DA transmission can have selective effects on motivated behavior, impairing some processes, whereas sparing others. Consistent with this, it has been suggested that interference with DA transmission impairs activational aspects of food motivation but leaves intact directional aspects (Salamone 1988, 1997, 1992; Barbano and Cador 2006). This idea is not only related to locomotion or schedule-induced activity but is also highly relevant for food-reinforced instrumental behaviors. Instrumental behaviors can be characterized by a high degree of vigor, persistence, or effort. This characteristic of behavior has enormous adaptive significance because it enables organisms to overcome obstacles or work-related response costs that separate them from significant stimuli. A substantial body of evidence indicates that mesolimbic DA is involved in regulating work-related functions. Food-motivated tasks that have minimal response requirements tend to be relatively insensitive to the interference with DA transmission, whereas tasks that involve greater response costs, such as operant conditioning schedules with high ratio requirements, tend to be more sensitive to DA manipulations.

Early studies showed that doses of DA antagonists that impaired lever pressing had little effect on reinforced nose-poking behavior (Ettenberg et al. 1981) or on the response of simply being in proximity to the food dish on an interval schedule (Salamone 1986), which suggests that the effects of DA antagonism interacts with the 
kinetic requirements of the instrumental response. Caul and Brindle (2001) demonstrated that the effects of haloperidol on food-reinforced behavior were dependent upon which operant schedule was used (i.e., FR1 vs progressive ratio). The effects of accumbens DA depletions also depend greatly upon the ratio requirement of the schedule being used. Ishiwari et al. (2004) reported that accumbens DA depletions that substantially impaired lever pressing on a fixed ratio of 5 (FR5) schedule had no significant effect on FR1 performance. Aberman and Salamone (1999) studied the effects of accumbens DA depletions across a wide range of ratio schedules (FR1, 4, 16 , and 64) and observed that ratio requirement was an important determinant of the effects of DA depletions (that is, responding on FR16 and FR64 schedules was severely impaired; Fig. 1a). A similar pattern was observed when rats were tested across a range of ratio schedules as high as FR300 (i.e., FR5 to FR300), even when the macroscopic density of food delivered per lever press was kept constant (Salamone et al. 2001). Although it is generally observed that there is recovery of behavioral function after DA depletions (Zigmond et al. 1984; Salamone et al. 1990; Correa et al. 2002), this effect also appears to depend upon the ratio requirement; although responding on FR4 or FR5 schedules exhibited rapid recovery (i.e., 1-2 weeks) after DA depletions (Aberman and Salamone 1999; Salamone et al. 1993a,b; Ishiwari et al. 2004), and responding on FR16 and FR64 schedules showed a more persistent deficit (Aberman and Salamone 1999). Thus, the magnitude of the ratio requirement appears to be a critical determinant of sensitivity to the effects of accumbens DA depletions.

An important consideration in interpreting these studies is that factors other than work requirements also could contribute to the differential task sensitivity shown by animals with DA depletions. Although baseline response rate contributes to the response slowing shown by DAdepleted animals responding on some schedules (Salamone et al. 1999, 2003, 2006), this does not appear to be the primary determinant of the 'crashing' or 'ratio strain' shown by DA-depleted rats when ratios are very high (Salamone et al. 2001). Another possible factor is time (Cardinal et al. 2000; Salamone et al. 2001). It takes more time to complete a schedule with a higher ratio requirement than one with a lower requirement, and thus, it is possible that the intermittence of a schedule (i.e., long time periods without reinforcement) could be a determinant of the schedule dependency shown by animals with accumbens DA depletions or DA antagonism. Some studies have compared the effects of accumbens DA depletions on the performance of regular VI schedules and VI schedules that have additional ratio requirements attached (i.e., tandem VI/ FR schedules). In this way, one can assess the effects of DA a Effect of DA Depletion
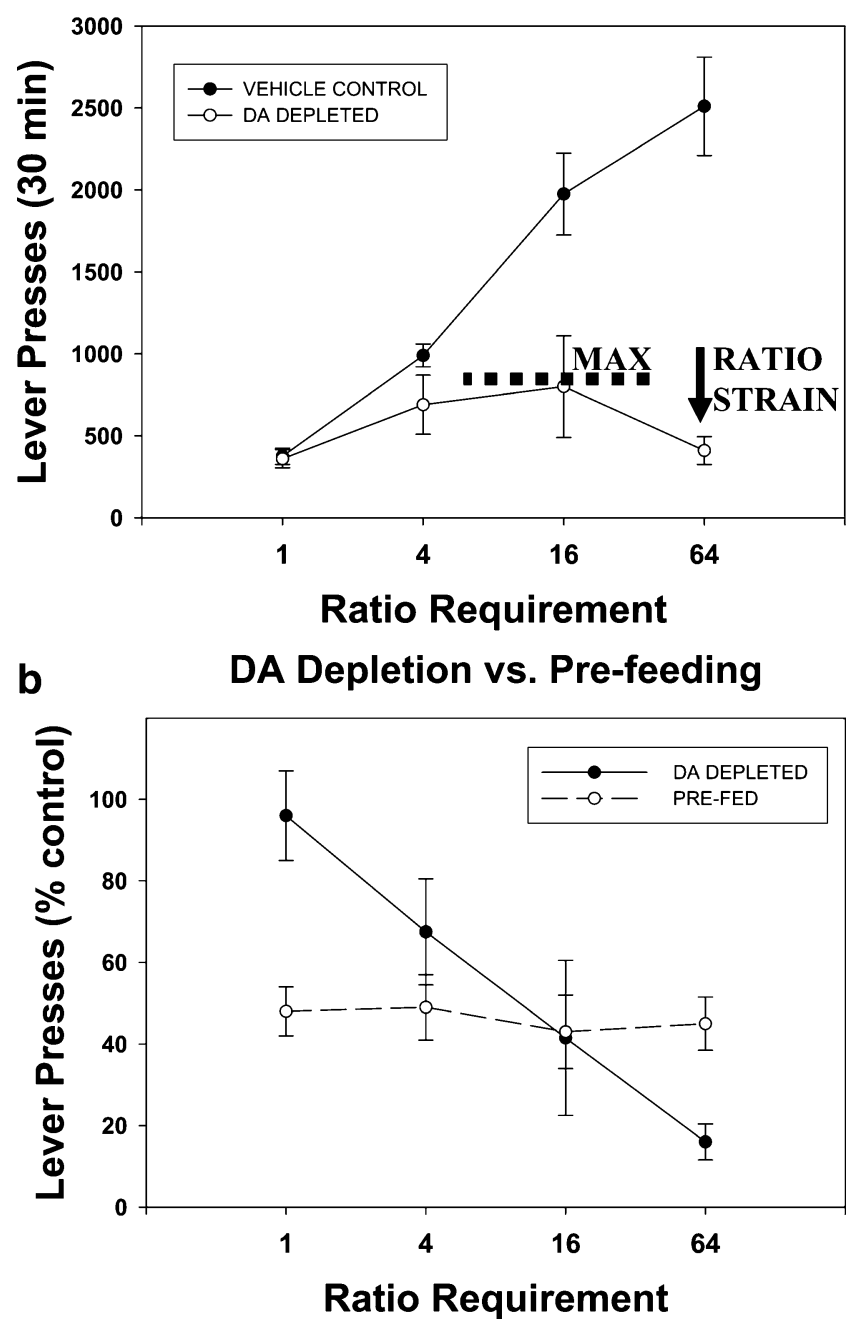

Fig. 1 a Effects of accumbens DA depletions on lever pressing across schedules with different ratio requirements. Mean $( \pm \mathrm{SEM})$ number of lever presses across a 30-min session is shown (data are from Aberman and Salamone 1999). Nucleus accumbens DA depletions reduced the maximal rate of responding (thick broken line, MAX) and also produced "ratio strain" (arrow); that is, they altered the relation between ratio level and response output and made animals much more sensitive to schedules with high ratio requirements. Overall, nucleus accumbens DA depletions have been described as having two major actions on ratio performance: they blunt the response activating effects of low-to-moderate ratio requirements, and they enhance the response suppressing effects of high ratio requirements (Salamone and Correa 2002). As observed in the original Aberman and Salamone (1999) paper, in economic terms, nucleus accumbens DA depletions reduce the elasticity of demand for food. b Although nucleus accumbens DA depletions slow responding, induce ratio strain, and alter elasticity of demand for food, they do not do so in a way that closely resembles the effects of reinforcer devaluations such as pre-feeding to food motivation. This panel compares the results of the DA depletion experiment shown in Fig. 2a with the results of a parallel experiment in which rats were pre-fed to reduce food motivation (data from Aberman and Salamone 1999). In Fig. 2b, data from both experiments are expressed as percent of control responding. It can be seen that the pattern of effects produced by accumbens DA depletions differ markedly from the effects produced by pre-feeding 
depletions on schedules with different ratio requirements that nevertheless have the same time requirements. Accumbens DA depletions impaired responding on a VI 30-s schedule that had a FR5 component attached (i.e., a tandem VI 30-s/FR5 schedule) but did not affect lever pressing on a comparable VI 30-s schedule (Correa et al. 2002). Mingote et al. (2005) investigated a group of tandem VI/FR schedules that had larger ratio requirements and spanned a larger range of time intervals (i.e., VI 60 s vs VI 60 s/FR10, and VI $120 \mathrm{~s}$ vs VI $120 \mathrm{~s} / \mathrm{FR} 10)$. Accumbens DA depletions did not significantly affect VI 60 or $120 \mathrm{~s}$ performance when no added ratio was attached but did suppress response rate on the two tandem schedules that had FR10 requirements added (Mingote et al. 2005). There were signs of response slowing (i.e., reductions in short inter-response times) and also response fragmentation (i.e., increases in the number of pauses) in DA-depleted rats. Taken together, these studies demonstrate that ratio requirements, over and above any effect of time requirements, make rats sensitive to the effects of accumbens DA depletions. This observation is consistent with recent reports showing that responding on a progressive interval schedule was not impaired by intra-accumbens injections of DA antagonists (Wakabayashi et al. 2004) and that delay discounting was not affected by accumbens DA depletions (Winstanley et al. 2005).

To summarize, the imposition of a ratio requirement presents a significant obstacle to animals with impaired DA transmission in the accumbens. This clearly identifies at least one dimension of work output and effort expenditure that is highly dependent upon accumbens DA function. Other aspects of work, such as overcoming weight or force requirements, may involve less dependence upon DA transmission (Ishiwari et al. 2004; Fowler et al. 1986). Factors such as density of reinforcement and time requirements, although important determinants of instrumental behavior, cannot easily explain why animals with accumbens DA depletions are so sensitive to schedules with high ratio requirements. In addition, the effects of accumbens DA depletions on ratio schedules do not appear to be dependent upon changes in appetite or primary food motivation. Although the FR1 schedule is sensitive to extinction and reinforcer devaluations such as pre-feeding to reduce food motivation, this schedule is relatively insensitive to the effects of accumbens DA depletions (Aberman and Salamone 1999; Ishiwari et al. 2004). Moreover, the effects of pre-feeding on operant performance across a range of ratio schedules are distinct from the effects of DA depletions on ratio performance (Aberman and Salamone 1999; see Fig. 1b). Based upon these findings and related studies, it has been suggested that a major function of accumbens DA is to enable animals to overcome work-related response costs that separate them from significant stimuli (Salamone et al. 1991, 1993a, 1997, 2003, 2005; Sokolowski and Salamone 1998; Aberman et al. 1998; Aberman and Salamone 1999).

\section{Nucleus accumbens DA and effort-related decision making}

Organisms need to exert effort to overcome response constraints that separate them from biologically relevant stimuli and must constantly make effort-related decisions involving cost/benefit assessments across a wide variety of stimuli and responses (van den Bos et al. 2006). As well as being involved in the exertion of effort, evidences indicate that accumbens DA is part of the forebrain circuitry involved in effort-related decision making and that interference with accumbens DA transmission alters the outcome of cost/benefit analyses involving work-related response costs. One of the procedures that has been used to assess effort-related decision making is a task that offers rats a choice between lever pressing to obtain a relatively preferred food (e.g. Bioserve pellets) vs approaching and consuming a less preferred food (lab chow), which is concurrently available in the chamber. Untreated rats responding on a FR1 or FR5 schedule typically get most of their food by lever pressing, and they consume only small amounts of chow (Salamone et al. 1991). This procedure is sensitive to the ratio requirement of the operant behavior component of the task, as increases up to FR10 and FR20 lead to shifts in choice behavior away from lever pressing and towards chow intake (Salamone et al. 1997). Most studies have been conducted with the concurrent FR5/chow intake version of this task, in which the animals get most of their food from lever pressing. The DA antagonists cisflupenthixol, haloperidol, raclopride, SCH 23390, and SKF83566 all decreased lever pressing for food but substantially increased intake of the concurrently available chow (Salamone et al. 1991, 1996; Cousins et al. 1994; Salamone and Correa 2002; Koch et al. 2000; see Fig. 2). The low dose of haloperidol that produced this effect $(0.1 \mathrm{mg} / \mathrm{kg})$ did not alter food intake or preference in freefeeding choice tests (Salamone et al. 1991; Koch et al. 2000). Although DA D1 and D2 family antagonists reduced FR 5 lever pressing and increased chow intake, the serotonergic appetite suppressant fenfluramine suppressed both lever pressing and chow intake (Salamone and Correa 2002), an effect similar to that produced by pre-feeding (Salamone et al. 1991). These findings are consistent with the hypothesis that low doses of DA antagonists do not suppress lever pressing simply because they reduce appetite.

Depletions of DA in medial neostriatum had no effect on the performance of the concurrent FR5/chow intake task 

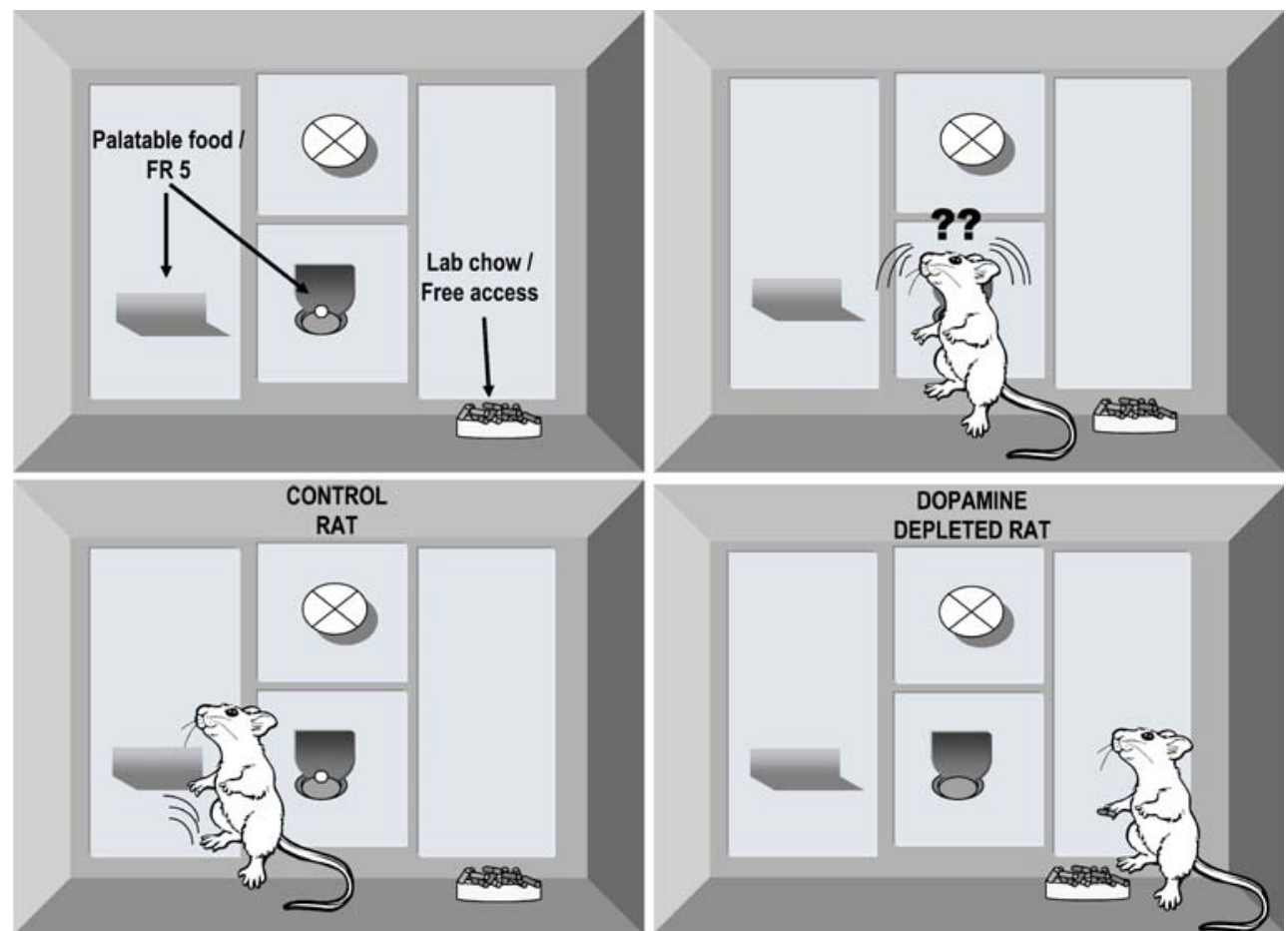

Fig. 2 These panels depict the conditions seen during the concurrent lever pressing/chow intake procedure used to assess effort-related decisions based upon cost/benefit analyses (Salamone et al. 1991, 1996; Salamone and Correa 2002). Top left The operant chamber allows for a high palatability food (high carbohydrate operant pellets) to be accessible through lever pressing. A less preferred food (laboratory chow) is concurrently available in the chamber. Top right

The animal has a choice between pressing the lever and feeding on the concurrently available chow. Bottom left If the ratio requirement is low enough (e.g., FR5), untreated rats get most of their food from lever pressing and eat little of the chow. Bottom right Rats treated with low doses of DA antagonists, or with accumbens DA depletions, shift their choice behavior away from lever pressing and increase consumption of the alternative food source (i.e., chow)

(Cousins et al. 1993). Ventrolateral neostriatal DA depletions impaired movement but did not shift behavior from lever pressing to chow intake instead decreasing both behaviors (Cousins et al. 1993). In fact, the accumbens is the DA terminal region at which interference with DA transmission mimics the effects of low doses of systemic DA antagonists. Accumbens DA depletions and local intraaccumbens injections of D1 or D2 antagonists decrease lever pressing and increase chow intake (Salamone et al. 1991; Cousins et al. 1993; Cousins and Salamone 1994; Sokolowski and Salamone 1998; Nowend et al. 2001; Koch et al. 2000). The accumbens is divided into distinct subregions (Meredith et al. 1992; Zahm and Brog 1992; Zahm 2000), and the shift from lever pressing to chow intake on the concurrent choice task has been shown to occur if injections of a D1 or D2 family antagonist are given into the medial core, lateral core, or dorsal shell subregions of the accumbens (Nowend et al. 2001; Salamone et al. 1991). In contrast to the effects shown with rats that have impaired DA transmission, recent evidence indicates that DA transporter knockout mice, which have enhanced DA transmission, show increased selection of lever pressing relative to chow intake with this task (Cagniard et al. 2006).

A T-maze procedure also has been developed to assess the effects of DA manipulations on effort-related choice (Salamone et al. 1994). With this procedure, two arms of the maze can have different reinforcement densities (e.g., four vs two food pellets or four vs zero), and under some conditions, a 44-cm barrier can be placed in the arm with the higher reward density to vary task difficulty. Under conditions in which no barrier was present in the arm with the high reinforcement density, untreated rats preferred that arm, and neither haloperidol nor accumbens DA depletion altered arm preference (Salamone et al. 1994). When the arm with the barrier contained four pellets but the other arm contained no pellets (that is, the only way to get food was to climb the barrier), rats with accumbens DA depletions were very slow but still chose the high density arm, climb the barrier, and consume the pellets (Cousins et al. 1996). Yet, accumbens DA depletions dramatically altered choice behavior when the high-density arm (four pellets) had the barrier in place and the arm without the barrier contained an alternative food source ( 2 pellets). Under these conditions, DA depleted rats showed decreased choice of the highdensity arm, and increased choice of the low-density arm (Cousins et al. 1996; Salamone et al. 1994). Studies employing the T-maze choice task support the hypothesis 
that accumbens DA depletions cause animals to alter their instrumental response selection based upon the work requirements of the task (Salamone et al. 1997, 2003, 2005, 2006).

Taken together, these studies have demonstrated that rats with impaired DA transmission remain directed towards the acquisition and consumption of food despite their diminished tendency to emit responses with high rate or speed. Faced with the challenge of work-related response costs, these rats show a compensatory reallocation of behavior, selecting a low-cost alternative path to a different food source (i.e., the available chow or the arm with less food). These findings, along with other empirical and computational approaches (Niv et al. 2007; Phillips et al. 2007), indicate that mesolimbic DA is a critical component of the forebrain circuitry regulating effort-related processes.

\section{Forebrain circuitry involved in effort-related decision making}

The T-maze task described above has been employed to investigate the functions of other brain areas in addition to the accumbens. Several papers have examined the effects of cortical lesions on effort-related processes. Walton et al. (2002) studied the effects of medial frontal cortex lesions that included prelimbic, infralimbic, and anterior cingulate cortex (ACC). Medial frontal cortex lesions shifted the behavior of the rats away from the arm that contained the high density of reinforcement, which was obstructed by a barrier. Instead, rats with lesions increased selection of the arm with no barrier. However, medial frontal cortex lesions did not alter choice behavior when the rats were tested under conditions in which both arms had a barrier. Moreover, rats with lesions did not shift away from the arm with the barrier if the height of the barrier was reduced. The effort-related effects of lesions of different frontal cortical areas were studied further in a subsequent paper (Walton et al. 2003). Lesions of prelimbic and infralimbic cortex did not affect choice behavior, but lesions of ACC produced the same changes in effort-related choice that had been shown previously with the larger lesions. Several recent studies have focused upon the role of the ACC in effort-related choice. The effects of ACC lesions appear to depend upon the specific task, as these lesions were shown to alter effort-related choice in the T-maze task but not in operant choice tasks (Schweimer and Hauber 2005). Although ACC catecholamine depletions failed to affect T-maze choice behavior in one study (Walton et al. 2005), another paper did observe such deficits (Schweimer et al. 2005), which is possibly due to higher doses of 6-OHDA being used in the Schweimer et al. (2005) study. Floresco and Ghods-Sharifi (2006) recently investigated the inter- action between the ACC and the basolateral amygdala in the regulation of effort-based decision making using the T-maze choice task. Bilateral injections of the local anesthetic bupivacaine into the basolateral amygdala reduced preference for the high-barrier arm with the higher reinforcement density. These effects were not due to problems with spatial function or deficits in gross motor function. Moreover, Floresco and Ghods-Sharifi (2006) showed that unilateral activation of the basolateral amygdala combined with a contralateral inactivation of ACC also disrupted effort-based decision making. These findings support the hypothesis that serial transfer of information between basolateral amygdala and ACC is involved in work-related decision making.

The results of these experiments involving neocortical and limbic areas are consistent with the earlier studies that focused upon accumbens DA. Lesions or inactivation of ACC, as well as inactivation of the basolateral amygdala, altered effort-related choice in the T-maze task and produced effects similar to those previously shown for low doses of haloperidol and nucleus accumbens DA depletions. This research indicates that the accumbens is part of the forebrain circuitry involved in the regulation of

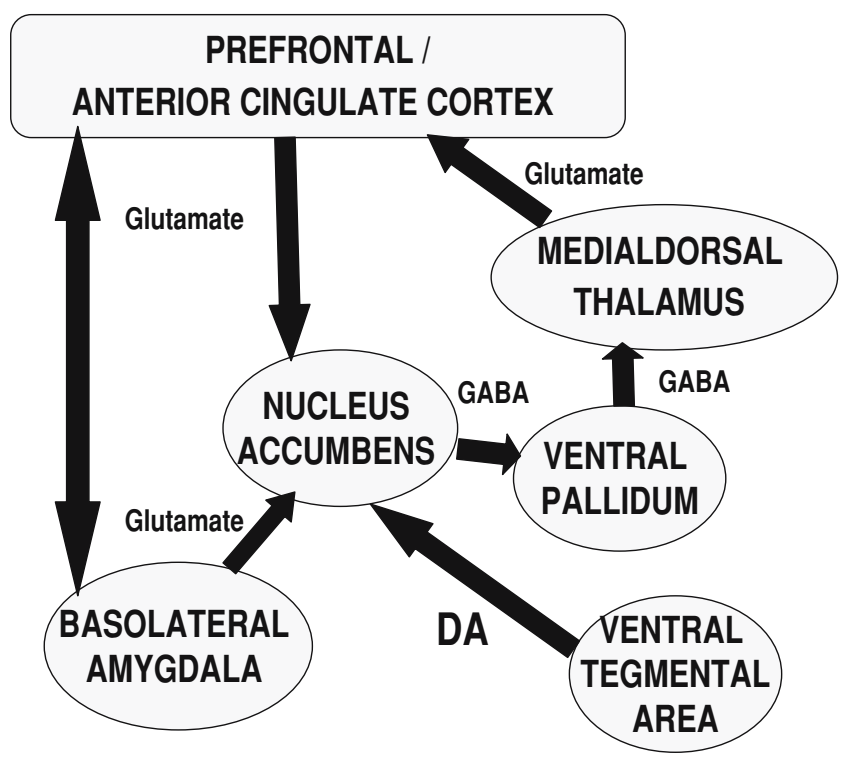

Fig. 3 Anatomical circuit diagram showing some of the connections linking cortical/limbic/striatal structures that are involved in effortrelated processes (connections drawn are based upon Fallon and Moore 1978; Nauta et al. 1978; McDonald 1991; Brog et al. 1993; Groenewegen et al. 1996; Zahm 2000; Zahm and Heimer 1990). Projection patterns of distinct accumbens subregions (Meredith et al. 1992; Zahm and Brog 1992; Zahm 2000) are not shown. Functional distinctions between core and shell are important for many motivated behaviors (Cardinal et al. 2002), but their importance for effort-related processes is still unknown (Sokolowski and Salamone 1998; Nowend et al. 2001). Parallel circuitry involving neostriatal areas has been implicated facilitating and sustaining execution of "motor programs" (Young and Penney 1993), which may be related to some of the functions of DA discussed in the present review 
behavioral activation and effort-related decision-making (Fig. 3). Nucleus accumbens receives inputs from frontal cortex and limbic areas that are interconnected with each other and also receives DA inputs from ventral tegmental area. GABAergic neurons from the accumbens project to pallidal regions (e.g. ventral pallidum), which in turn send projections to thalamic nuclei that relay information to neocortex. Nucleus accumbens, frontal cortex, and basolateral amygdala appear to be critical components of this circuitry (Rushworth et al. 2004; Salamone et al. 2006; Floresco and Ghods-Sharifi 2006), and additional research needs to be conducted to investigate the role played by other anatomical structures and other transmitters.

Recent experiments have begun to focus upon the effortrelated functions of GABA in the ventral pallidum (VP), which receives GABAergic input from the accumbens (Groenewegen and Russchen 1984; Zahm and Brog 1992). VP neurons project to mediodorsal thalamus and various brainstem motor areas (Zahm and Brog 1992; Groenewegen et al. 1996), and it has been hypothesized that VP acts as a relay station and also as an integrator of information related to diverse limbic and striatal inputs (Kretschmer 2000). VP injections of GABA suppressed locomotion (Jones and Mogenson 1979), and noveltyinduced locomotion was reduced by VP injections of the $\mathrm{GABA}_{\mathrm{A}}$ agonist muscimol (Austin and Kalivas 1990; Hooks and Kalivas 1995). Based upon these studies, it was hypothesized that stimulation of VP GABA receptors should produce many of the same behavioral effects as DA depletion in accumbens. Using the concurrent FR5 lever pressing/chow intake procedure, it was recently demonstrated that infusions of the $\mathrm{GABA}_{\mathrm{A}}$ agonist muscimol into the lateral VP decreased lever pressing for the preferred food but substantially increased consumption of the less preferred chow (Farrar et al. 2005; Font-Hurtado et al. 2006). These results suggest that VP also is a component of the brain circuitry regulating effort-related processes and, perhaps, is a critical link in the transfer of effort-related information from the accumbens to other brain areas. Another possible component of the neural system regulating effort-related processes is adenosine $\mathrm{A}_{2 \mathrm{~A}}$ receptors. There is an interaction between DA and adenosine $\mathrm{A}_{2 \mathrm{~A}}$ receptors in striatal areas (Svenningsson et al. 1999; Wang et al. 2001; Hettinger et al. 2001; Chen et al. 2001). This interaction usually is studied using animal models of motor function related to parkinsonism (Ferré et al. 1997, 2001; Svenningsson et al. 1999; Jenner 2003, 2005; Hauber et al. 2001; Pinna et al. 2005), but less is known about the motivational functions of adenosine $\mathrm{A}_{2 \mathrm{~A}}$ transmission (e.g., O'Neill and Brown 2006). Recent studies were undertaken to determine if adenosine $\mathrm{A}_{2 \mathrm{~A}}$ antagonism would reverse the effects of DA antagonism on tasks related to response output and effort-related decision making. The adenosine
$\mathrm{A}_{2 \mathrm{~A}}$ antagonist MSX-3 (Hockemeyer et al. 2004) increased FR5 lever pressing in rats treated with $0.1 \mathrm{mg} / \mathrm{kg}$ haloperidol and also reversed the haloperidol-induced shift from lever pressing to chow intake on the concurrent FR5/ chow intake task (Farrar et al. 2007). These results indicate that there is a functional interaction between DA and adenosine $A_{2 \mathrm{~A}}$ receptors that is involved in the regulation of effort-related processes.

In summary, it is evident that there has been a rapid growth in our understanding of the brain circuitry involved in effort-related functions (Salamone et al. 2003; Walton et al. 2006; Phillips et al. 2007). Accumbens DA is an important part of this circuitry, but it is only one part; several transmitters across multiple brain regions are involved in these functions, and researchers are only beginning to sketch the outline of all the potential brain systems that are involved. Presently, it is not clear which brain areas are involved in the exertion of effort and which ones are more selectively involved in the perception of effort or the decision making process; future research will be necessary to further distinguish those functions. Research in this area is critical because it has helped to identify brain mechanisms involved in important aspects of motivation. Moreover, identification of the brain systems involved in regulating behavioral activation and effortbased choice in animals may provide important clues regarding the brain systems that are involved in clinical psychopathologies related to psychomotor retardation in depression.

\section{Clinical significance of effort-related functions: importance for understanding psychomotor slowing, anergia, and fatigue}

In addition to playing an important role in non-pathological aspects of motivation, behavioral activation functions also have considerable clinical significance. Although depression is defined as an affective disorder, with cardinal symptoms that include negative affect and mood alterations, some of the most common symptoms of depression are energy-related dysfunctions such as tiredness, listlessness, and fatigue (Tylee et al. 1999; Stahl 2002; Salamone et al. 2006). This group of symptoms has been referred to in various ways, including "psychomotor slowing", "psychomotor retardation", "fatigue" and "anergia", and these energy-related dysfunctions also are a critical aspect of other disorders as well (Tylee et al. 1999; Swindle et al. 2001; Stahl 2002; Salamone et al. 2006). Although the biological basis of the impaired psychomotor function seen in depression and other disorders is uncertain, considerable evidence implicates central DA systems (van Praag and Korf 1971; Willner 1983; Rogers et al. 1987; Brown and 
Gershon 1993; Flint et al. 1993; Caligiuri and Ellwanger 2000; Volkow et al. 2001; Stahl 2002). There is reported to be an association between parkinsonism and depression with psychomotor slowing (Rogers et al. 1987), and despite the fact that antiparkinsonian drugs such as L-dopa and bromocriptine have mixed antidepressant characteristics with regard to other symptoms of depression, they do tend to improve anergia (Brown and Gershon 1993). Depressed patients with psychomotor retardation have speech articulation disorders that are very similar to those shown by parkinsonian patients (Flint et al. 1993). Caligiuri and Ellwanger (2000) studied motor performance in depressed patients and observed that motor slowing in depression is behaviorally very similar to parkinsonian bradykinesia. They suggested that motor slowing in depression and parkinsonism could result from common underlying mechanisms, and that reduced DA transmission could play an important role in the expression of motor slowing in depression. Schmidt et al. (2001) reported that reduced DA transmission in psychiatric patients is not related to anhedonia, but instead is related to psychomotor slowing and decreased interaction with the environment. Psychomotor slowing was the psychiatric symptom most strongly associated with reduced levels of DA transporter density in a PET study of methamphetamine abusers (Volkow et al. 2001). The efficacy of several antidepressant drugs for reversing psychomotor slowing in depressed patients was related to the ability of these drugs to inhibit DA uptake (Rampello et al. 1991). Stimulants that enhance DA transmission also have been used to treat energy-related symptoms in depressed people (Demyttenaere et al. 2005). Several other psychiatric disorders in addition to depression also are characterized by the presence of energy-related dysfunctions. For example, there are people who have severe motivational disturbance that has been labeled as psychomotor slowing, anergia, or apathy, yet these individuals do not meet the diagnostic criteria for depression (Marin 1996; Campbell and Duffy 1997). Energy-related symptoms in these people can be ameliorated with the DA agonist bromocriptine, and it has been suggested that DA is involved in this type of syndrome (Marin 1996; Campbell and Duffy 1997). The DA uptake inhibitor buproprion improved apathy symptoms in patients with depression and organic brain disease (Corcoran et al. 2004).

A number of imaging studies implicate various components of the striatal/limbic/cortical circuitry in clinical aspects of energy-related functions in humans. Changes in cerebral blood flow in dorsolateral prefrontal cortex were shown to be associated with the presence of psychomotor retardation (Bench et al. 1993). Reduced metabolic activity in left prefrontal cortex was related to psychomotor retardation in depressed patients (Brody et al. 2001a,b), and PET measures of increased metabolic activity in anterior cingulate cortex were associated with improvements in psychomotor retardation in patients with major depressive disorder (Brody et al. 2001b). Changes in cerebral blood flow in left neostriatum were related to reaction time in patients with major depression, with patients having the greatest psychomotor slowing showed the smallest increases in task-stimulated striatal blood flow (Hickie et al. 1999). A recent MRI study demonstrated that decreased nucleus accumbens volume was associated with apathy but not with depression in patients with HIV infections (Paul et al. 2005).

Together with the animal studies focused on effortrelated functions of DA, these clinical findings are consistent with the hypothesis that DA systems are involved in behavioral activation. Overall, there is a striking similarity between the brain systems implicated in effort-related processes in animals and those involved in energy dysfunctions in humans. Studies of psychomotor slowing and effort-related functions in animals could be useful as model systems for investigating processes involved in energy-related dysfunctions in humans. For example, based upon the observation that adenosine $\mathrm{A}_{2 \mathrm{~A}}$ antagonism can reverse the effort-related effects of impaired DA transmission in rats, it has been suggested that adenosine $\mathrm{A}_{2 \mathrm{~A}}$ antagonists could be useful as treatments for psychomotor slowing in depression (Farrar et al. 2007). Additional research in this area could lead to novel treatments for energy-related dysfunctions in humans.

\section{Summary and conclusions}

For years, the behavioral functions of mesolimbic DA have been the subject of intense investigation. There is a general agreement that DA in nucleus accumbens participates in many functions that are important for instrumental behavior, but researchers are still grappling with the details of this involvement. In drawing conclusions, it is useful to consider some of the general lessons that several decades of research in neuropsychopharmacology and neuropsychology have provided. One clear lesson is that global functions such as "reward", "reinforcement", "motivation", and "motor control" are actually composed of several distinct processes, many of which can be dissociated from each other. Manipulations of the brain with drugs or lesions can dissociate processes from each other because these treatments can severely impair one process while leaving another largely or completely intact. This general observation, applied to the specific case of dopaminergic involvement in instrumental behavior, leads one to the conclusion that interference with DA transmission does not impair "reward" in any general sense because too many fundamental aspects of reward are left intact by these manipu- 
lations. Interference with DA transmission impairs some functions related to instrumental behavior while leaving fundamental aspects of primary motivation for natural reinforcers (e.g., appetite for food, primary food reward) basically intact. Yet, despite the preservation of some critical features of "reward" in DA-depleted animals, accumbens DA does appear to be particularly important for overcoming work-related requirements that separate animals from significant stimuli. This represents one, but certainly not the only function of mesolimbic DA.

Another lesson that can be drawn is that the traditional functional terms typically used in psychology do not easily map onto particular brain systems in a selective or exclusive way (Luria 1969). A good example of this is the ongoing discussion of the involvement of accumbens DA in aspects of motivation and motor control (see also Salamone 1992). Although one could attempt to establish a strict dichotomy between the motivational functions of nucleus accumbens and those functions that are generally classed within the realm of motor or sensorimotor processes, this is not a necessary conceptual organization. As an alternative to such a dichotomy, it can be argued that "motor control" and "motivation", although somewhat distinct conceptually, overlap considerably in terms of some of the specific characteristics of behavior being described (Salamone 1987, 1992; Salamone and Correa 2002; Salamone et al. 2003, 2005, 2006). Consistent with this line of thinking, it is reasonable to suggest that accumbens DA performs functions that represent areas of overlap between motor and motivational processes. Such functions would include the types of behavioral activation and effort-related functions discussed above. Nucleus accumbens DA is important for enabling animals to respond to the work-related challenges imposed by ratio schedules (Aberman and Salamone 1999; Correa et al. 2002; Salamone and Correa 2002; Salamone et al. 2003, 2005, 2006; Mingote et al. 2005) and barriers in mazes (Salamone et al. 1994; Cousins et al. 1996). In summarizing their results in a recent PET study in humans, Knutson et al. (2003) suggested that nucleus accumbens "may provide the motivational 'engine' that fuels attainment of immediate rewards" (p 271). Phasic DA release is thought to provide a window of opportunistic drive during which the threshold cost expenditure to obtain the reward is increased (Phillips et al. 2007). Nucleus accumbens DA regulates response speed and the exertion of effort in reinforcer-seeking behavior, and participates with other brain areas in the regulation of decisions based upon effort expenditure. Thus, accumbens DA performs functions that can be classed as "motor", "sensorimotor", or "limbic/motor" in a very broad sense, but which nevertheless also represent important aspects of motivation. The activational functions of nucleus accumbens DA are not only critical for aspects of motivation for natural stimuli, but they also are important for drug-seeking behavior. Drug use and abuse not only involve numerous psychological functions, including reinforcement, learning, motivation, emotion, habit formation, and compulsiveness, but they also involve effort. Over the last few years, there has been a growing emphasis placed upon effort-related processes that are involved in drug reinforcement (Marinelli et al. 1998; Nadal et al. 2002; Vezina et al. 2002; Czachowski et al. 2002; Colby et al. 2003). In addition, activational aspects of motivation are important for understanding various neuropsychiatric conditions, and continuing research on the relation between psychomotor slowing in depression and the symptoms of parkinsonism only serves to highlight this consideration of the relation between motivation and motor control processes (Salamone et al. 2006).

Of course, this emphasis on behavioral activation is not intended to diminish the role that DA plays in other aspects of incentive motivation and instrumental learning. As noted above and emphasized in previous papers (Salamone et al. 2005), it is doubtful that accumbens DA performs only one function, and evidence in favor of the hypothesis that DA is involved in the exertion of effort or effort-related decision making is not incompatible with the hypothesized involvement of this system in instrumental learning (Wise 2004; Beninger and Gerdjikov 2004; Kelley et al. 2005; Baldo and Kelley 2007), aspects of incentive motivation (Wyvell and Berridge 2001; Berridge 2007), or pavlovian-instrumental transfer (Everitt and Robbins 2005). Although the incentive salience hypothesis (Berridge 2007) differs in detail from many of the ideas presented in the present paper, there are also some areas of potential agreement; it has been suggested that accumbens DA depletions could be thought of as affecting some aspects of "wanting" (e.g., energy to obtain reinforcers; effort in reinforcement-seeking behavior; Salamone and Correa 2002; Salamone et al. 2003, 2006), while leaving other aspects (e.g., appetite for food) basically intact. Moreover, the suggested involvement of accumbens DA in behavioral activation and effort is related to the hypothesis that nucleus accumbens is important for facilitating responsiveness to the activating properties of pavlovian conditioned stimuli (Everitt et al. 1999; Di Ciano et al. 2001; Parkinson et al. 2002; Everitt and Robbins 2005; Day et al. 2006) because behavioral responsiveness to discrete, temporal, and contextual pavlovian cues associated with reinforcer availability is a critical aspect of behavioral activation (Salamone 1997; Salamone et al. 1997, 2001, 2003, 2005; Everitt and Robbins 2005; Robbins and Everitt 2007). In summary, the decline of the traditional form of the DA hypothesis of "reward" is leading to an era of novel experimental approaches and rich conceptual restructuring. Studies of the role of accumbens DA in behavioral activation, effort- 
related processes, and other behavioral functions are leading to a deeper understanding of the brain mechanisms regulating distinct aspects of motivation, and also are serving to underscore the relation between motivational processes and the regulation of action.

Acknowledgment Much of the work cited in this review was supported by grants to JDS from the US NSF and NIH/NIMH, NIDA, and NINDS.

\section{References}

Aberman JE, Salamone JD (1999) Nucleus accumbens dopamine depletions make rats more sensitive to high ratio requirements but do not impair primary food reinforcement. Neuroscience 92:545-552

Aberman JE, Ward SJ, Salamone JD (1998) Effects of dopamine antagonists and accumbens dopamine depletions on time-constrained progressive-ratio performance. Pharmacol Biochem Behav 61:341-348

Aharon I, Becerraa L, Chabris CF, Borsooka D (2006) Noxious heat induces fMRI activation in two anatomically distinct clusters within the nucleus accumbens. Neurosci Lett 392:159164

Ahn S, Phillips AG (2007) Dopamine efflux in the nucleus accumbens during within-session extinction, outcome-dependent, and habit-based instrumental responding for food reward. Psychopharmacology (in this issue)

Anstrom KK, Woodward DJ (2005) Restraint increases dopaminergic burst firing in awake rats. Neuropsychopharmacology 30:18321840

Aparicio C (2003a) Efectos del haloperidol en un medio ambiente de reforzamiento variable. Rev Mex Anâl Conducta 29:169-190

Aparicio C (2003b) El haloperidol afecta la elección y cambia la preferencia: el Paradigma de Elección con Barrera. Rev Mex Anâl Conducta 29:33-63

Austin MC, Kalivas PW (1990) Enkephalinergic and GABAergic modulation of motor activity in the ventral pallidum. J Pharmacol Exp Ther 252:1370-1377

Bakshi VP, Kelley AE (1991) Dopaminergic regulation of feeding behavior: I. Differential effects of haloperidol microinjection in three striatal subregions. Psychobiology 19:223-232

Baldo BA, Kelley AE (2007) Distinct neurochemical coding of discrete motivational processes: insights from nucleus accumbens control of feeding. Psychopharmacology (submitted)

Baldo BA, Sadeghian K, Basso AM, Kelley AE (2002) Effects of selective dopamine D1 or D2 receptor blockade within nucleus accumbens subregions on ingestive behavior and associated motor activity. Behav Brain Res 137:165-177

Barbano MF, Cador M (2006) Differential regulation of the consummatory, motivational and anticipatory aspects of feeding behavior by dopaminergic and opioidergic drugs. Neuropsychopharmacol 31:1371-1381

Barbano MF, Cador M (2007) Opioids for hedonic experience and dopamine to get ready for it. Psychopharmacology (in this issue)

Barnes TD, Kubota Y, Hu D, Jin DZ, Graybiel AM (2005) Activity of striatal neurons reflects dynamic encoding and recoding of procedural memories. Nature 437:1158-1161

Barrett LF (2006) Are emotions natural kinds? Persp Psychol Sci $1: 28-58$

Bartoshuk AK (1971) Motivation. In: Kling JW, Riggs LA (eds) Woodworth \& Schlosberg's experimental psychology. Holt, Rinehart and Winston, New York, pp 793-846
Baum WM, Rachlin HC (1969) Choice as time allocation. J Exp Anal Behav 12:861-874

Bench CJ, Friston KJ, Brown RG, Frackowiak RS, Dolan RJ (1993) Regional cerebral blood flow in depression measured by positron emission tomography: the relationship with clinical dimensions. Psychol Med 23:579-590

Beninger RJ, Gerdjikov T (2004) The role of signaling molecules in reward-related incentive learning. Neurotox Res 6:91-104

Berridge KC (2000) Measuring hedonic impact in animals and infants: microstructure of affective taste reactivity patterns. Neurosci Biobehav Rev 24:173-198

Berridge KC (2007) What does dopamine do for reward today? Psychopharmacology (in this issue)

Berridge KC, Robinson TE (1998) What is the role of dopamine in reward: hedonic impact, reward learning, or incentive salience? Brain Res Brain Res Rev 28:309-369

Berridge KC, Venier IL, Robinson TE (1989) Taste reactivity analysis of 6-hydroxydopamine-induced aphagia: implications for arousal and anhedonia hypotheses of dopamine function. Behav Neurosci 103:36-45

Bickel WK, Marsch LA, Carroll ME (2000) Deconstructing relative reinforcing efficacy and situating the measures of pharmacological reinforcement with behavioral economics: a theoretical proposal. Psychopharmacology (Berl) 153:44-56

Blackburn JR, Phillips AG, Fibiger HC (1989) Dopamine and preparatory behavior: III. Effects of metoclopramide and thioridazine. Behav Neurosci 103:903-906

Blazquez PM, Fujii N, Kojima J, Graybiel AM (2002) A network representation of response probability in the striatum. Neuron 33:973-982

Blundell JE (1987) Structure, process and mechanism: case studies in the psychopharmacology of feeding. In: Iverson LL, Iversen SD, Snyder SH (eds) Handbook of psychopharmacology. Plenum, New York, pp 123-182

Bowers W, Hamilton M, Zacharko RM, Anisman H (1985) Differential effects of pimozide on response-rate and choice accuracy in a self-stimulation paradigm in mice. Pharmacol Biochem Behav 22:521-526

Brauer LH, De Wit H (1997) High dose pimozide does not block amphetamine-induced euphoria in normal volunteers. Pharmacol Biochem Behav 56:265-272

Brody AL, Barsom MW, Bota RG, Saxena S (2001a) Prefrontalsubcortical and limbic circuit mediation of major depressive disorder. Semin Clin Neuropsychiatry 6:102-112

Brody AL, Saxena S, Mandelkern MA, Fairbanks LA, Ho ML, Baxter LR (2001b) Brain metabolic changes associated with symptom factor improvement in major depressive disorder. Biol Psychiatry 50:171-178

Brog JS, Salyapongse A, Deutch AY, Zahm DS (1993) The patterns of afferent innervation of the core and shell in the accumbens part of the rat ventral striatum-Immunohistochemical detection of retrogradely transported fluoro-gold. J Comp Neurol 338:255-278

Brown AS, Gershon S (1993) Dopamine and depression. J Neural Transm Gen Sect 91:75-109

Burgdorf J, Panksepp J (2006) The neurobiology of positive emotions. Neurosci Biobehav Rev 30:173-187

Caine SB, Koob GF (1994) Effects of mesolimbic dopamine depletion on responding maintained by cocaine and food. J Exp Anal Behav 61:213-221

Cagniard B, Balsam PD, Brunner D, Zhuang X (2006) Mice with chronically elevated dopamine exhibit enhanced motivation, but not learning, for a food reward. Neuropsychopharmacol 31:1362-1370

Caligiuri MP, Ellwanger J (2000) Motor and cognitive aspects of motor retardation in depression. J Affect Disord 57:83-93

Campbell JJ, Duffy JD (1997) Treatment strategies in amotivated patients. Psychiatr Ann 27:44-49 
Cannon CM, Bseikri MR (2004) Is dopamine required for natural reward? Physiol Behav 81:741-748

Cardinal RN, Robbins TW, Everitt BJ (2000) The effects of damphetamine, chlordiazepoxide, alpha-flupenthixol and behavioural manipulations on choice of signalled and unsignalled delayed reinforcement in rats. Psychopharmacology (Berl) 152:362-375

Cardinal RN, Parkinson JA, Hall J, Everitt BJ (2002) Emotion and motivation: the role of the amygdala, ventral striatum, and prefrontal cortex. Neurosci Biobehav Rev 26:321-352

Caul WF, Brindle NA (2001) Schedule-dependent effects of haloperidol and amphetamine: multiple-schedule task shows withinsubject effects. Pharmacol Biochem Behav 68:53-63

Chen JF, Moratalla R, Impagnatiello F, Grandy DK, Cuellar B, Rubinstein M, Beilstein MA, Hacket E, Fink JS, Low MJ, Ongini E, Schwarzschild MA (2001) The role of the D2 dopamine receptor (D2R) in A2a adenosine-receptor (A2aR) mediated behavioral and cellular responses as revealed by A2a and D2 receptor knockout mice. Proc Natl Acad Sci 98:19701975

Chevrette J, Stellar JR, Hesse GW, Markou A (2002) Both the shell of the nucleus accumbens and the central nucleus of the amygdala support amphetamine self-administration in rats. Pharmacol Biochem Behav 71:501-507

Choi WY, Balsam PD, Horvitz JC (2005) Extended habit training reduces dopamine mediation of appetitive response expression. J Neurosci 25:6729-6733

Clifton PG (2000) Meal patterning in rodents: psychopharmacological and neuroanatomical studies. Neurosci Biobehav Rev 24:213222

Clifton PG, Rusk IN, Cooper SJ (1991) Effects of dopamine D1 and dopamine D2 antagonists on the free feeding and drinking patterns of rats. Behav Neurosci 105:272-281

Cofer CN, Appley MH (1964) Motivation: theory and research. Wiley, New York

Colby CR, Whisler K, Steffen C, Nestler EJ, Self DW (2003) Striatal cell type-specific overexpression of DeltaFosB enhances incentive for cocaine. J Neurosci 23:2488-2493

Collier GH, Jennings W (1969) Work as a determinant of instrumental performance. J Comp Physiol Psychol 68:659-662

Corcoran C, Wong ML, O'Keane V (2004) Bupropion in the management of apathy. J Psychopharmacol 18:133-135

Correa M, Carlson BB, Wisniecki A, Salamone JD (2002) Nucleus accumbens dopamine and work requirements on interval schedules. Behav Brain Res 137:179-187

Correa M, Salamone JD (2006) Implicación del componente hedónico en el uso y abuso de drogas. In J. Juarez (ed) Neurobiología del Hedonismo en la Conducta. Mexico City: Manual Moderno (in press)

Cousins MS, Salamone JD (1994) Nucleus accumbens dopamine depletions in rats affect relative response allocation in a novel cost/benefit procedure. Pharmacol Biochem Behav 49:85-91

Cousins MS, Sokolowski JD, Salamone JD (1993) Different effects of nucleus accumbens and ventrolateral striatal dopamine depletions on instrumental response selection in the rat. Pharmacol Biochem Behav 46:943-951

Cousins MS, Wei W, Salamone JD (1994) Pharmacological characterization of performance on a concurrent lever pressing/feeding choice procedure: effects of dopamine antagonist, cholinomimetic, sedative and stimulant drugs. Psychopharmacology (Berl) 116:529-537

Cousins MS, Atherton A, Turner L, Salamone JD (1996) Nucleus accumbens dopamine depletions alter relative response allocation in a T-maze cost/benefit task. Behav Brain Res 74:189-197

Cousins MS, Trevitt J, Atherton A, Salamone JD (1999) Different behavioral functions of dopamine in the nucleus accumbens and ventrolateral striatum: a microdialysis and behavioral investigation. Neuroscience 91:925-934

Czachowski CL, Santini LA, Legg BH, Samson HH (2002) Separate measures of ethanol seeking and drinking in the rat: effects of remoxipride. Alcohol 28:39-46

Das S, Fowler SC (1996) An update of Fowler and Das: anticholinergic reversal of haloperidol-induced, within-session decrements in rats' lapping behavior. Pharmacol Biochem Behav 53:853-855

Datla KP, Ahier RG, Young AM, Gray JA, Joseph MH (2002) Conditioned appetitive stimulus increases extracellular dopamine in the nucleus accumbens of the rat. Eur J Neurosci 16:19871993

Day JJ, Wheeler RA, Roitman MF, Carelli RM (2006) Nucleus accumbens neurons encode Pavlovian approach behaviors: evidence from an autoshaping paradigm. Eur $\mathrm{J}$ Neurosci 23:1341-1351

Delfs JM, Schreiber L, Kelley AE (1990) Microinjection of cocaine into the nucleus accumbens elicits locomotor activation in the rat. J Neurosci 10:303-310

Demyttenaere K, De Fruyt J, Stahl SM (2005) The many faces of fatigue in major depressive disorder. Int $\mathbf{J}$ Neuropsychopharmacol 8:93-105

Di Chiara G (2002) Nucleus accumbens shell and core dopamine: differential role in behavior and addiction. Behav Brain Res 137:75-114

Di Ciano P, Cardinal RN, Cowell RA, Little SJ, Everitt BJ (2001) Differential involvement of NMDA, AMPA/kainate, and dopamine receptors in the nucleus accumbens core in the acquisition and performance of pavlovian approach behavior. J Neurosci 21:9471-9477

Dickinson A, Balleine B (1994) Motivational control of goal-directed action. Anim Learn Behav 22:1-18

Dinsmoor JA (2004) The etymology of basic concepts in the experimental analysis of behavior. J Exp Anal Behav 82:311-316

Duffy E (1963) Activation and Behavior. Wiley, New York

Dunnett SB, Iversen SD (1982) Regulatory impairments following selective 6-OHDA lesions of the neostriatum. Behav Brain Res 4:195-202

Ettenberg A, Koob GF, Bloom FE (1981) Response artifact in the measurement of neuroleptic-induced anhedonia. Science 213:357-359

Evenden JL, Robbins TW (1983) Dissociable effects of d-amphetamine, chlordiazepoxide and alpha-flupenthixol on choice and rate measures of reinforcement in the rat. Psychopharmacology (Berl) 79:180-186

Everitt BJ, Robbins TW (2005) Neural systems of reinforcement for drug addiction: from actions to habits to compulsion. Nat Neurosci 8:1481-1489

Everitt BJ, Parkinson JA, Olmstead MC, Arroyo M, Robledo P, Robbins TW (1999) Associative processes in addiction and reward. The role of amygdala-ventral striatal subsystems. Ann NY Acad Sci 877:412-438

Falk JL (1971) The nature and determinants of adjunctive behavior. Physiol Behav 6:577-588

Fallon JH, Moore RY (1978) Catecholamine innervation of the basal forebrain. IV. Topography of the dopamine projection to the basal forebrain and neostriatum. J Comp Neurol 180:545-580

Farrar AM, Vontell R, Ramos R, Mingote S, Salamone JD (2005) Forebrain circuitry involved in effort-related decision making: ventral pallidal GABA receptor stimulation alters response allocation in food-seeking behavior Program No. 891.17.2005 Abstract Viewer/Itinerary Planner. Washington, DC: Society for Neuroscience, Online.

Farrar AM, Pereira M, Velasco F, Hockemeyer J, Müller CE, Salamone JD (2007) Adenosine A2A receptor antagonism reverses the effects of dopamine receptor antagonism on instrumental output 
and effort-related choice in the rat. Implications for studies of psychomotor slowing. Psychopharmacology (in this issue)

Ferré S, Freidholm BB, Morelli M, Popoli P, Fuxe K (1997) Adenosine-dopamine receptor-receptor interactions as an integrative mechanism in the basal ganglia. Trends Neurosci 20:482487

Ferré S, Popoli P, Gimenez-Llort L, Rimondini R, Müller CE, Stromberg I, Orgen O, Fuxe K (2001) Adenosine/dopamine interaction: implications for the treatment of Parkinson's disease. Parkinson Rel Disord 7:235-241

Fibiger HC, Carter DA, Phillips AG (1976) Decreased intracranial self-stimulation after neuroleptics or 6-hydroxydopamine: evidence for mediation by motor deficits rather than by reduced reward. Psychopharmacology (Berl) 47:21-27

Flint AJ, Black SE, Campbell-Taylor I, Gailey GF, Levinton C (1993) Abnormal speech articulation, psychomotor retardation, and subcortical dysfunction in major depression. J Psychiatr Res 27:309-319

Floresco SB, Ghods-Sharifi S (2006) Amygdala-prefrontal cortical circuitry regulates effort-based decision making. Cereb Cortex (in press)

Font-Hurtado L, Farrar AM, Mingote S, Salamone JD (2006) Forebrain circuitry involved in effort-related decision-making: injections of $\mathrm{GABA}_{\mathrm{A}}$ agonist muscimol into ventral pallidum, but not a dorsal control site, alters response allocation in food-seeking behavior. Program No. 71.13.2006 Abstract Viewer/Itinerary Planner. Washington, DC: Society for Neuroscience, Online

Fowler SC, Mortell C (1992) Low doses of haloperidol interfere with rat tongue extensions during licking: a quantitative analysis. Behav Neurosci 106:386-395

Fowler SC, LaCerra MM, Ettenberg A (1986) Effects of haloperidol on the biophysical characteristics of operant responding: implications for motor and reinforcement processes. Pharmacol Biochem Behav 25:791-796

Gardner EL (1992) Brain reward mechanisms. In: Lowinson JH, Ruiz P, Millman RB (eds) Substance abuse. Williams and Wilkins, New York, pp 70-99

Gardner EL (2005) Endocannabinoid signaling system and brain reward: emphasis on dopamine. Pharmacol Biochem Behav 81:263-284

Gawin FH (1986) Neuroleptic reduction of cocaine-induced paranoia but not euphoria? Psychopharmacology (Berl) 90:142-143

Graybiel AM (1998) The basal ganglia and chunking of action repertoires. Neurobiol Learn Mem 70:119-136

Groenewegen HJ, Russchen FT (1984) Organization of the efferent projections of the nucleus accumbens to pallidal, hypothalamic, and mesencephalic structures: a tracing and immunohistochemistry study. J Comp Neurol 223:347-367

Groenewegen HJ, Wright CI, Beijer AV (1996) The nucleus accumbens: gateway for limbic structures to reach the motor system? Prog Brain Res 107:485-511

Guarraci FA, Kapp BS (1999) An electrophysiological characterization of ventral tegmental area dopaminergic neurons during differential pavlovian fear conditioning in the awake rabbit. Behav Brain Res 99:169-179

Gunne LM, Anggard E, Jonsson LE (1972) Clinical trials with amphetamine-blocking drugs. Psychiatr Neurol Neurochir 75:225-226

Haney M, Ward AS, Foltin RW, Fischman MW (2001) Effects of ecopipam, a selective dopamine D1 antagonist, on smoked cocaine self-administration by humans. Psychopharmacology (Berl) 155:330-337

Hauber W, Neuscheler P, Nagel J, Müller CE (2001) Catalepsy induced by a blockade of dopamine D1 or D2 receptors was reversed by a concomitant blockade of adenosine A2a receptors in the caudate putamen of rats. Eur J Neurosci 14:1287-1293
Hettinger BD, Lee A, Linden J, Rosin DL (2001) Ultrastructural localization of adenosine A2A receptors suggests multiple cellular sites for modulation of GABAergic neurons in rat striatum. J Comp Neurol 431:331-346

Hickie I, Ward P, Scott E, Haindl W, Walker B, Dixon J, Turner K (1999) Neo-striatal rCBF correlates of psychomotor slowing in patients with major depression. Psychiatry Res 92:75-81

Higgins ET (2006) Value from hedonic experience and engagement. Psychol Rev 113:439-460

Hockemeyer J, Burbiel JC, Müller CE (2004) Multigram-scale syntheses, stability, and photoreactions of A2A adenosine receptor antagonists with 8-styrylxanthine structure: potential drugs for Parkinson's disease. J Org Chem 69:3308-3318

Hooks MS, Kalivas PW (1995) The role of mesoaccumbens-pallidal circuitry in novelty-induced behavioral activation. Neuroscience 64:587-597

Horvitz JC (2000) Mesolimbocortical and nigrostriatal dopamine responses to salient non-reward events. Neuroscience 96:651-656

Horvitz JC, Richardson WB, Ettenberg A (1993) Dopamine receptor blockade and reductions in thirst produce differential effects on drinking behavior. Pharmacol Biochem Behav 45:725-728

Hsiao S, Chen BH (1995) Complex response competition and dopamine blocking: choosing of high cost sucrose solution versus low cost water in rats. Chin J Physiol 38:99-109

Huang AC, Hsiao S (2002) Haloperidol attenuates rewarding and aversively conditioned suppression of saccharin solution intake: reevaluation of the anhedonia hypothesis of dopamine blocking. Behav Neurosci 116:646-650

Hursh SR, Raslear TG, Shurtleff D, Bauman R, Simmons L (1988) A cost-benefit analysis of demand for food. J Exp Anal Behav 50:419-440

Hull EM, Weber MS, Eaton RC, Dua R, Markowski VP, Lumley L, Moses J (1991) Dopamine receptors in the ventral tegmental area affect motor, but not motivational or reflexive, components of copulation in male rats. Brain Res 554:72-76

Ikemoto S, Panksepp J (1996) Dissociations between appetitive and consumatory response by pharmocological manipulations of reward-relevant brain regions. Behav Neurosci 110:331-345

Ishiwari K, Weber SM, Mingote S, Correa M, Salamone JD (2004) Accumbens dopamine and the regulation of effort in foodseeking behavior: modulation of work output by different ratio or force requirements. Behav Brain Res 151:83-91

Jenner P (2003) A2A antagonists as novel non-dopaminergic therapy for motor dysfunction in PD. Neurology 61:S32-38

Jenner P (2005) Istradefylline, a novel adenosine A2A receptor antagonist, for the treatment of Parkinson's disease. Exp Opin Investig Drugs 14:729-738

Jensen J, McIntosh AR, Crawley AP, Mikulis DJ, Remington G, Kapur S (2003) Direct activation of the ventral striatum in anticipation of aversive stimuli. Neuron 40:1251-1257

Jicha GA, Salamone JD (1991) Vacuous jaw movements and feeding deficits in rats with ventrolateral striatal dopamine depletion: possible relation to parkinsonian symptoms. J Neurosci 11:38223829

Jones DL, Mogenson GJ (1979) Oral motor performance following central dopamine receptor blockade. Eur J Pharmacol 59:11-21

Keedwell PA, Andrew C, Williams SC, Brammer MJ, Phillips ML (2005) The neural correlates of anhedonia in major depressive disorder. Biol Psychiatry 58:843-853

Kelley AE (2004) Ventral striatal control of appetitive motivation: role in ingestive behavior and reward-related learning. Neurosci Biobehav Rev 27:765-776

Kelly PH, Seviour PW, Iversen SD (1975) Amphetamine and apomorphine responses in the rat following 6-OHDA lesions of the nucleus accumbens septi and corpus striatum. Brain Res 94:507-522 
Kelley AE, Baldo BA, Pratt WE, Will MJ (2005) Corticostriatalhypothalamic circuitry and food motivation: integration of energy, action and reward. Physiol Behav 86:773-795

Killcross AS, Everitt BJ, Robins TW (1997) Symmetrical effects of amphetamine and alpha-flupenthixol on conditioned punishment and conditioned reinforcement: contrasts with midazolam. Psychopharmacology (Berl) 129:141-152

Killeen PR (1975) On the temporal control of behavior. Psychol Rev 82:89-115

Killeen PR, Hanson SJ, Osborne SR (1978) Arousal: its genesis and manifestation as response rate. Psychol Rev 85:571-581

Knutson B, Fong GW, Adams CM, Varner JL, Hommer D (2001) Dissociation of reward anticipation and outcome with eventrelated fMRI. Neuroreport 12:3683-3687

Knutson B, Fong GW, Bennett SM, Adams CM, Hommer D (2003) A region of mesial prefrontal cortex tracks monetarily rewarding outcomes: characterization with rapid event-related fMRI. Neuroimage 18:263-272

Koch M, Schmid A, Schnitzler HU (2000) Role of nucleus accumbens dopamine D1 and D2 receptors in instrumental and Pavlovian paradigms of conditioned reward. Psychopharmacology (Berl) 152:67-73

Koob GF, Swerdlow NR (1988) The functional output of the mesolimbic dopamine system. Ann NY Acad Sci 537:216-227

Koob GF, Riley SJ, Smith SC, Robbins TW (1978) Effects of 6hydroxydopamine lesions of the nucleus accumbens septi and olfactory tubercle on feeding, locomotor activity, and amphetamine anorexia in the rat. J Comp Physiol Psychol 92:917-927

Krebs JR (1977) Optimal foraging: theory and experiment. Nature 268:583-584

Kretschmer BD (2000) Functional aspects of the ventral pallidum. Amino Acids 19:201-210

Kuhn TS (1962) The structure of scientific revolutions. University of Chicago Press, Chicago

Lapish CC, Kroener S, Durstewitz D, Lavin A, Seamans JK (2007) The ability of the mesocortical dopamine system to operate in distinct temporal modes. Psychopharmacology (in this issue)

Lavin A, Nogueira L, Lapish CC, Wightman RM, Phillips PE, Seamans JK (2005) Mesocortical dopamine neurons operate in distinct temporal domains using multimodal signaling. J Neurosci 25:5013-5023

Lea SEG (1978) The psychology and economics of demand. Psychol Bull 85:441-466

Leyton M, Casey KF, Delaney JS, Kolivakis T, Benkelfat C (2005) Cocaine craving, euphoria, and self-administration: a preliminary study of the effect of catecholamine precursor depletion. Behav Neurosci 119:1619-1627

Li M, Parkes J, Fletcher PJ, Kapur S (2004) Evaluation of the motor initiation hypothesis of APD-induced conditioned avoidance decreases. Pharmacol Biochem Behav 78:811-819

Liberzon I, Taylor SF, Amdur R, Jung TD, Chamberlain KR, Minoshima S, Koeppe RA, Fig LM (1999) Brain activation in PTSD in response to trauma-related stimuli. Biol Psychiatry $45: 817-826$

Lindsley DB (1951) Emotion. In: Stevens SS (ed) Handbook of experimental psychology. Wiley, New York, pp 473-516

Ljungberg T (1987) Blockade by neuroleptics of water intake and operant responding for water in the rat: anhedonia, motor deficit, or both? Pharmacol Biochem Behav 27:341-350

Ljungberg T (1988) Scopolamine reverses haloperidol-attenuated lever-pressing for water but not haloperidol-attenuated water intake in the rat. Pharmacol Biochem Behav 29:205-208

Ljungberg T (1990) Differential attenuation of water intake and waterrewarded operant responding by repeated administration of haloperidol and SCH 23390 in the rat. Pharmacol Biochem Behav 35:111-115
Lopez-Crespo G, Rodriguez M, Pellon R, Flores P (2004) Acquisition of schedule-induced polydipsia by rats in proximity to upcoming food delivery. Learn Behav 32:491-499

Luria AR (1969) Human brain and psychological processes. In: Pribram KH (ed) Brain and behavior 1 mood, states and mind. Penguin, Baltimore, MD, pp 37-53

Marin RS (1996) Apathy: concept, syndrome, neural mechanisms, and treatment. Semin Clin Neuropsychiatry 1:304-314

Marinelli M, Barrot M, Simon H, Oberlander C, Dekeyne A, Le Moal M, Piazza PV (1998) Pharmacological stimuli decreasing nucleus accumbens dopamine can act as positive reinforcers but have a low addictive potential. Eur J Neurosci 10:3269-3275

Marinelli S, Pascucci T, Bernardi G, Puglisi-Allegra S, Mercuri NB (2005) Activation of TRPV1 in the VTA excites dopaminergic neurons and increases chemical- and noxious-induced dopamine release in the nucleus accumbens. Neuropsychopharmacology 30:864-870

Martin-Iverson MT, Wilkie D, Fibiger HC (1987) Effects of haloperidol and d-amphetamine on perceived quantity of food and tones. Psychopharmacology (Berl) 93:374-381

Matsumoto N, Hanakawa T, Maki S, Graybiel AM, Kimura M (1999) Role of nigrostriatal dopamine system in learning to perform sequential motor tasks in a predictive manner. J Neurophysiol 82:978-998

McCullough LD, Salamone JD (1992) Involvement of nucleus accumbens dopamine in the motor activity induced by periodic food presentation: a microdialysis and behavioral study. Brain Res 592:29-36

McCullough LD, Cousins MS, Salamone JD (1993a) The role of nucleus accumbens dopamine in responding on a continuous reinforcement operant schedule: a neurochemical and behavioral study. Pharmacol Biochem Behav 46:581-586

McCullough LD, Sokolowski JD, Salamone JD (1993b) A neurochemical and behavioral investigation of the involvement of nucleus accumbens dopamine in instrumental avoidance. Neuroscience 52:919-925

McDonald AJ (1991) Organization of amygaloid projections to the prefrontal cortex and associated striatum. Neuroscience 44: $1-14$

McLaughlin PJ, Winston KM, Limebeer CL, Parker LA, Makriyannis A, Salamone JD (2005) The cannabinoid CB1 antagonist AM 251 produces food avoidance and behaviors associated with nausea but does not impair feeding efficiency in rats. Psychopharmacology (Berl) 180:286-293

Meredith GE, Agolia R, Arts MPM, Groenewegen HJ, Zahm DS (1992) Morphological differences between projection neurons of the core and shell in the nucleus accumbens of the rat. Neuroscience 50:149-162

Mingote S, Weber SM, Ishiwari K, Correa M, Salamone JD (2005) Ratio and time requirements on operant schedules: effort-related effects of nucleus accumbens dopamine depletions. Eur J Neurosci 21:1749-1757

Mittleman G, Whishaw IQ, Jones GH, Koch M, Robbins TW (1990) Cortical, hippocampal, and striatal mediation of scheduleinduced behaviors. Behav Neurosci 104:399-409

Mogenson GJ, Jones DL, Yim CY (1980) From motivation to action: functional interface between the limbic system and the motor system. Prog Neurobiol 14:69-97

Moruzzi G, Magoun HW (1949) Brain stem reticular formation and activation of the EEG. EEG Clin Neurophysiol 1:455-473

Muscat R, Willner P (1989) Effects of dopamine receptor antagonists on sucrose consumption and preference. Psychopharmacology (Berl) 99:98-102

Nadal R, Armario A, Janak PH (2002) Positive relationship between activity in a novel environment and operant ethanol selfadministration in rats. Psychopharmacology 162:333-338 
Nader K, Bechara A, van der Kooy D (1997) Neurobiological constraints on behavioral models of motivation. Annu Rev Psychol 48:85-114

Nann-Vernotica E, Donny EC, Bigelow GE, Walsh SL (2001) Repeated administration of the D1/5 antagonist ecopipam fails to attenuate the subjective effects of cocaine. Psychopharmacology (Berl) 155:338-347

Nauta WJ, Smith JP, Faull RL, Domesick VB (1978) Efferent connections and nigral afferents of the nucleus accumbens septi in the rat. Neuroscience 3:385-401

Neill DB, Herndon JG Jr (1978) Anatomical specificity within rat striatum for the dopaminergic modulation of DRL responding and activity. Brain Res 153:529-538

Niv Y, Daw ND, Joel D, Dayan P (2007) Tonic dopamine: opportunity costs and the control of response vigor. Psychopharmacology (in this issue)

Nowend KL, Arizzi M, Carlson BB, Salamone JD (2001) D1 or D2 antagonism in nucleus accumbens core or dorsomedial shell suppresses lever pressing for food but leads to compensatory increases in chow consumption. Pharmacol Biochem Behav 69:373-382

Numan M, Numan MJ, Pliakou N, Stolzenberg DS, Mullins OJ, Murphy JM, Smith CD (2005) The effects of D1 or D2 dopamine receptor antagonism in the medial preoptic area, ventral pallidum, or nucleus accumbens on the maternal retrieval response and other aspects of maternal behavior in rats. Behav Neurosci 119:1588-1604

O’Doherty JP, Deichmann R, Critchley HD, Dolan RJ (2002) Neural responses during anticipation of a primary taste reward. Neuron 33:815-826

O'Neill M, Brown VJ (2006) The effect of the adenosine A(2A) antagonist KW-6002 on motor and motivational processes in the rat. Psychopharmacology 184:46-55

Packard MG, McGaugh JL (1996) Inactivation of hippocampus or caudate nucleus with lidocaine differentially affects expression of place and response learning. Neurobiol Learn Mem 65:65-72

Paredes RG, Agmo A (2004) Has dopamine a physiological role in the control of sexual behavior? A critical review of the evidence. Prog Neurobiol 73:179-226

Parkinson JA, Dalley JW, Cardinal RN, Bamford A, Fehnert B, Lachenal G, Rudarakanchana N, Halkerston KM, Robbins TW, Everitt BJ (2002) Nucleus accumbens dopamine depletion impairs both acquisition and performance of appetitive Pavlovian approach behaviour: implications for mesoaccumbens dopamine function. Behav Brain Res 137:149-163

Paul RH, Brickman AM, Navia B, Hinkin C, Malloy PF, Jefferson AL, Cohen RA, Tate DF, Flanigan TP (2005) Apathy is associated with volume of the nucleus accumbens in patients infected with HIV. J Neuropsych Clin Neurosci 17:167-171

Pereira M, Uriarte N, Agrati D, Zuluaga MJ, Ferreira A (2005) Motivational aspects of maternal anxiolysis in lactating rats. Psychopharmacology (Berl) 180:241-248

Peterson RL (2005) The neuroscience of investing: fMRI of the reward system. Brain Res Bull 67:391-397

Pezze MA, Feldon J (2004) Mesolimbic dopaminergic pathways in fear conditioning. Prog Neurobiol 74:301-320

Phan KL, Taylor SF, Welsh RC, Ho SH, Britton JC, Liberzon I (2004) Neural correlates of individual ratings of emotional salience: a trial-related fMRI study. Neuroimage 21:768-780

Phillips PE, Walton ME, Jhou TC (2007) Calculating utility: preclinical evidence for cost-benefit analysis by mesolimbic dopamine. Psychopharmacology (in this issue)

Pijnenburg AJ, Honig WM, Van Rossum JM (1975) Inhibition of damphetamine-induced locomotor activity by injection of haloperidol into the nucleus accumbens of the rat. Psychopharmacologia 41:87-95
Pinna A, Wardas J, Simola N, Morelli M (2005) New therapies for the treatment of Parkinson's disease: adenosine A2A receptor antagonists. Life Sci 77:3259-3267

Pisa M, Schranz JA (1988) Dissociable motor roles of the rat's striatum conform to a somatotopic model. Behav Neurosci 102:429-440

Pruessner JC, Champagne F, Meaney MJ, Dagher A (2004) Dopamine release in response to a psychological stress in humans and its relationship to early life maternal care: a positron emission tomography study using [11C]raclopride. J Neurosci 24:2825-2831

Rampello L, Nicoletti G, Raffaele R (1991) Dopaminergic hypothesis for retarded depression: a symptom profile for predicting therapeutical responses. Acta Psychiatr Scand 84:552-554

Redgrave P, Gurney K (2006) The short-latency dopamine signal: a role in discovering novel actions? Nat Rev Neurosci 7:967-975

Rick JH, Horvitz JC, Balsam PD (2006) Dopamine receptor blockade and extinction differentially affect behavioral variability. Behav Neurosci 120:488-492

Robbins TW, Everitt B (2007) A role for mesencephalic dopamine in activation: a commentary on Berridge (2007). Psychopharmacology (in this issue)

Robbins TW, Koob GF (1980) Selective disruption of displacement behaviour by lesions of the mesolimbic dopamine system. Nature 285:409-412

Robbins TW, Roberts DC, Koob GF (1983) Effects of d-amphetamine and apomorphine upon operant behavior and schedule-induced licking in rats with 6-hydroxydopamine-induced lesions of the nucleus accumbens. J Pharmacol Exp Ther 224:662-673

Roberts DC, Corcoran ME, Fibiger HC (1977) On the role of ascending catecholaminergic systems in intravenous self-administration of cocaine. Pharmacol Biochem Behav 6:615-620

Robinson S, Sandstrom SM, Denenberg VH, Palmiter RD (2005) Distinguishing whether dopamine regulates liking, wanting, and/or learning about rewards. Behav Neurosci 119:5-15

Roitman MF, Stuber GD, Phillips PE, Wightman RM, Carelli RM (2004) Dopamine operates as a subsecond modulator of food seeking. J Neurosci 24:1265-1271

Rogers D, Lees AJ, Smith E, Trimble M, Stern GM (1987) Bradyphrenia in Parkinson's disease and psychomotor retardation in depressive illness. An experimental study. Brain 110(Pt 3):761-776

Rolls ET, Rolls BJ, Kelly PH, Shaw SG, Wood RJ, Dale R (1974) The relative attenuation of self-stimulation, eating and drinking produced by dopamine-receptor blockade. Psychopharmacologia $38: 219-230$

Rubio-Chevannier H, Bach-Y-Rita G, Penaloza-Rojas J, HernandezPeon R (1961) Potentiating action of imipramine upon "reticular arousal". Exp Neurol 4:214-220

Rushworth MF, Walton ME, Kennerley SW, Bannerman DM (2004) Action sets and decisions in the medial frontal cortex. Trends Cogn Sci 8:410-417

Rusk IN, Cooper SJ (1994) Parametric studies of selective D1 or D2 antagonists: effects on appetitive and feeding behaviour. Behav Pharmacol 5:615-622

Salamone JD (1986) Different effects of haloperidol and extinction on instrumental behaviours. Psychopharmacology (Berl) 88:18-23

Salamone JD (1987) The actions of neuroleptic drugs on appetitive instrumental behaviors. In: Iversen LL, Iversen SD, Snyder SH (eds) Handbook of psychopharmacology. Plenum, New York, pp 575-608

Salamone JD (1988) Dopaminergic involvement in activational aspects of motivation: effects of haloperidol on schedule induced activity, feeding and foraging in rats. Psychobiology 16:196-206

Salamone JD (1991) Behavioral pharmacology of dopamine systems: a new synthesis. In: Willner P, Scheel-Kruger J (eds) The mesolimbic dopamine system: from motivation to action. Cambridge University Press, Cambridge, England, pp 599-613 
Salamone JD (1992) Complex motor and sensorimotor functions of striatal and accumbens dopamine: involvement in instrumental behavior processes. Psychopharmacology (Berl) 107:160-174

Salamone JD (1994) The involvement of nucleus accumbens dopamine in appetitive and aversive motivation. Behav Brain Res 61:117-133

Salamone JD (1996) The behavioral neurochemistry of motivation: methodological and conceptual issues in studies of the dynamic activity of nucleus accumbens dopamine. J Neurosci Methods 64:137-149

Salamone JD (2007) Functions of mesolimbic dopamine: changing concepts and shifting paradigms. Psychopharmacology (in this issue)

Salamone JD, Correa M (2002) Motivational views of reinforcement: implications for understanding the behavioral functions of nucleus accumbens dopamine. Behav Brain Res 137:3-25

Salamone JD, Zigmond MJ, Stricker EM (1990) Characterization of the impaired feeding behavior in rats given haloperidol or dopamine-depleting brain lesions. Neuroscience 39:17-24

Salamone JD, Steinpreis RE, McCullough LD, Smith P, Grebel D, Mahan K (1991) Haloperidol and nucleus accumbens dopamine depletion suppress lever pressing for food but increase free food consumption in a novel food choice procedure. Psychopharmacology (Berl) 104:515-521

Salamone JD, Kurth PA, McCullough LD, Sokolowski JD, Cousins MS (1993a) The role of brain dopamine in response initiation: effects of haloperidol and regionally specific dopamine depletions on the local rate of instrumental responding. Brain Res 628:218-226

Salamone JD, Mahan K, Rogers S (1993b) Ventrolateral striatal dopamine depletions impair feeding and food handling in rats. Pharmacol Biochem Behav 44:605-610

Salamone JD, Cousins MS, Bucher S (1994) Anhedonia or anergia? Effects of haloperidol and nucleus accumbens dopamine depletion on instrumental response selection in a T-maze cost/benefit procedure. Behav Brain Res 65:221-229

Salamone JD, Kurth P, McCullough LD, Sokolowski JD (1995) The effects of nucleus accumbens dopamine depletions on continuously reinforced operant responding: contrasts with the effects of extinction. Pharmacol Biochem Behav 50:437-443

Salamone JD, Cousins MS, Maio C, Champion M, Turski T, Kovach J (1996) Different behavioral effects of haloperidol, clozapine and thioridazine in a concurrent lever pressing and feeding procedure. Psychopharmacology (Berl) 125:105-112

Salamone JD, Cousins MS, Snyder BJ (1997) Behavioral functions of nucleus accumbens dopamine: empirical and conceptual problems with the anhedonia hypothesis. Neurosci Biobehav Rev 21:341-359

Salamone JD, Aberman JE, Sokolowski JD, Cousins MS (1999) Nucleus accumbens dopamine and rate of responding: Neurochemical and behavioral studies. Psychobiology 27:236-247

Salamone JD, Wisniecki A, Carlson BB, Correa M (2001) Nucleus accumbens dopamine depletions make animals highly sensitive to high fixed ratio requirements but do not impair primary food reinforcement. Neuroscience 105:863-870

Salamone JD, Correa M, Mingote S, Weber SM (2003) Nucleus accumbens dopamine and the regulation of effort in food-seeking behavior: implications for studies of natural motivation, psychiatry, and drug abuse. J Pharmacol Exp Ther 305:1-8

Salamone JD, Correa M, Mingote SM, Weber SM (2005) Beyond the reward hypothesis: alternative functions of nucleus accumbens dopamine. Curr Opin Pharmacol 5:34-41

Salamone JD, Correa M, Mingote SM, Weber SM, Farrar AM (2006) Nucleus accumbens dopamine and the forebrain circuitry involved in behavioral activation and effort-related decision making: implications of understanding anergia and psychomotor slowing and depression. Curr Psychiatr Rev 2:267-280

Santi AN, Parker LA (2001) The dopamine antagonist, alphaflupenthixol, interferes with naloxone-induced place aversion learning, but not with acute opiate dependence in rats. Pharmacol Biochem Behav 70:193-197

Sarchiapone M, Carli V, Camardese G, Cuomo C, Di Guida D, Calgagni ML, Focacci C, De Riso S (2006) Dopamine transporter binding in depressed patients with anhedonia. Psychiatr Res Neuroimag 147:243-248

Schmidt K, Nolte-Zenker B, Patzer J, Bauer M, Schmidt LG, Heinz A (2001) Psychopathological correlates of reduced dopamine receptor sensitivity in depression, schizophrenia, and opiate and alcohol dependence. Pharmacopsychiatry 34:66-72

Schoenbaum G, Setlow B (2003) Lesions of nucleus accumbens disrupt learning about aversive outcomes. J Neurosci 23:9833-9841

Schultz W (2002) Getting formal with dopamine and reward. Neuron $36: 241-263$

Schweimer J, Hauber W (2005) Involvement of the rat anterior cingulate cortex in control of instrumental responses guided by reward expectancy. Learn Mem 12:334-342

Schweimer J, Saft S, Hauber W (2005) Involvement of catecholamine neurotransmission in the rat anterior cingulate in effort-related decision making. Behav Neurosci 119:1687-1692

Sienkiewicz-Jarosz H, Scinska A, Kuran W, Ryglewicz D, Rogowski A, Wrobel E, Korkosz A, Kukwa A, Kostowski W, Bienkowski P (2005) Taste responses in patients with Parkinson's disease. J Neurol Neurosurg Psychiatry 76:40-46

Smith-Roe SL, Kelley AE (2000) Coincident activation of NMDA and dopamine D1 receptors within the nucleus accumbens core is required for appetitive instrumental learning. J Neurosci 20:7737-7742

Smith GP (1995) Dopamine and food reward. Prog Psychobiol Physiol Psychol 16:83-144

Smith GP (2004) Accumbens dopamine mediates the rewarding effect of orosensory stimulation by sucrose. Appetite 43:11-13

Spence KW (1956) Behavior Theory and Conditioning. New Haven: Yale University Press

Sotak BN, Hnasko TS, Robinson S, Kremer EJ, Palmiter RD (2005) Dysregulation of dopamine signaling in the dorsal striatum inhibits feeding. Brain Res 1061:88-96

Sokolowski JD, Salamone JD (1998) The role of accumbens dopamine in lever pressing and response allocation: effects of 6-OHDA injected into core and dorsomedial shell. Pharmacol Biochem Behav 59:557-566

Staddon JER, Simmelhag VL (1971) The superstition experiment: a re-examination of its implications for the principles of adaptive behavior. Psychol Rev 78:3-43

Stahl SM (2002) The psychopharmacology of energy and fatigue. J Clin Psychiatry 63:7-8

Stefurak TL, van der Kooy D (1994) Tegmental pedunculopontine lesions in rats decrease saccharin's rewarding effects but not its memory-improving effect. Behav Neurosci 108:972-980

Stellar JR (2001) Reward. In: Winn P (ed) Dictionary of biological psychology. Routledge, London, p 679

Svenningsson P, Le Moine C, Fisone G, Fredholm BB (1999) Distribution, biochemistry and function of striatal adenosine A2A receptors. Prog Neurobiol 59:355-396

Swerdlow NR, Mansbach RS, Geyer MA, Pulvirenti L, Koob GF, Braff DL (1990) Amphetamine disruption of prepulse inhibition of acoustic startle is reversed by depletion of mesolimbic dopamine. Psychopharmacology (Berl) 100:413-416

Swindle R et al (2001) Energy and improved workplace productivity in depression. In: Sorkin A, Summers K, Farquhar I (eds) Investing in health: the social and economic benefits of health care innovation. Elsevier, Amsterdam, The Netherlands, pp 323-341

Tidey JW, Miczek KA (1996) Social defeat stress selectively alters mesocorticolimbic dopamine release: an in vivo microdialysis study. Brain Res 721:140-149 
Treit D, Berridge KC (1990) A comparison of benzodiazepine, serotonin, and dopamine agents in the taste-reactivity paradigm. Pharmacol Biochem Behav 37:451-456

Tylee A, Gastpar M, Lepine JP, Mendlewicz J (1999) DEPRES II (Depression Research in European Society II): a patient survey of the symptoms, disability and current management of depression in the community. DEPRES Steering Committee. Int Clin Psychopharmacol 14:139-151

Ungerstedt U (1971) Adipsia and aphagia after 6-hydroxydopamine induced degeneration of the nigro-striatal dopamine system. Acta Physiol Scand 367(Suppl):95-122

Ungless MA (2004) Dopamine: the salient issue. Trends Neurosci 27:702-706

van den Bos R, van der Harst J, Jonkman S, Schilders M, Spruijt B (2006) Rats assess costs and benefits according to an internal standard. Behav Brain Res 171:350-354

van Praag HM, Korf J (1971) Current developments in the field of antidepressive agents. Ned Tijdschr Geneeskd 115:1963-1970

Vezina P, Lorrain DS, Arnold GM, Austin JD, Suto N (2002) Sensitization of midbrain dopamine neuron reactivity promotes the pursuit of amphetamine. J Neurosci 22:4654-4662

Volkow ND, Chang L, Wang GJ, Fowler JS, Leonido-Yee M, Franceschi D, Sedler MJ, Gatley SJ, Hitzemann R, Ding YS, Logan J, Wong C, Miller EN (2001) Association of dopamine transporter reduction with psychomotor impairment in methamphetamine abusers. Am J Psychiatry 158:377-382

Wachtel SR, Ortengren A, de Wit H (2002) The effects of acute haloperidol or risperidone on subjective responses to methamphetamine in healthy volunteers. Drug Alcohol Depend 68: 23-33

Wakabayashi KT, Fields HL, Nicola SM (2004) Dissociation of the role of nucleus accumbens dopamine in responding to reward-predictive cues and waiting for reward. Behav Brain Res 154:19-30

Wallace M, Singer G, Finlay J, Gibson S (1983) The effect of 6OHDA lesions of the nucleus accumbens septum on scheduleinduced drinking, wheelrunning and corticosterone levels in the rat. Pharmacol Biochem Behav 18:129-136

Walton ME, Bannerman DM, Rushworth MF (2002) The role of rat medial frontal cortex in effort-based decision making. J Neurosci 22:10996-11003

Walton ME, Bannerman DM, Alterescu K, Rushworth MF (2003) Functional specialization within medial frontal cortex of the anterior cingulate for evaluating effort-related decisions. J Neurosci 23:6475-6479

Walton ME, Croxson PL, Rushworth MF, Bannerman DM (2005) The mesocortical dopamine projection to anterior cingulate cortex plays no role in guiding effort-related decisions. Behav Neurosci 119:323-328

Walton ME, Kennerley SW, Bannerman DM, Phillips PE, Rushworth MF (2006) Weighing up the benefits of work: behavioral and neural analyses of effort-related decision making. Neural Netw 19:1302-1314

Wang GJ, Volkow ND, Logan J, Pappas NR, Wong CT, Zhu W, Netusil N, Fowler JS (2001) Brain dopamine and obesity. Lancet 357:354-357

Weissenborn R, Blaha CD, Winn P, Phillips AG (1996) Scheduleinduced polydipsia and the nucleus accumbens: electrochemical measurements of dopamine efflux and effects of excitotoxic lesions in the core. Behav Brain Res 75:147-158

White NM (1989) Reward or reinforcement: what's the difference? Neurosci Biobehav Rev 13:181-186

Willner P (1983) Dopamine and depression: a review of recent evidence. I. Empirical Studies. Brain Res Rev 6:211-224

Winstanley CA, Theobald DE, Dalley JW, Robbins TW (2005) Interactions between serotonin and dopamine in the control of impulsive choice in rats: therapeutic implications for impulse control disorders. Neuropsychopharmacology 30:669-682

Wise RA (1982) Neuroleptics and operant behavior: the anhedonia hypothesis. Behav Brain Sci 5:39-87

Wise RA (1985) The anhedonia hypothesis: Mark III. Behav Brain Sci 8:178-186

Wise RA (2004) Dopamine, learning and motivation. Nat Rev Neurosci 5:483-494

Wise RA, Colle LM (1984) Pimozide attenuates free feeding: best scores analysis reveals a motivational deficit. Psychopharmacology (Berl) 84:446-451

Wise RA, Raptis L (1985) Effects of pre-feeding on food-approach latency and food consumption speed in food deprived rats. Physiol Behav 35:961-963

Wise RA, Spindler J, deWit H, Gerberg GJ (1978a) Neurolepticinduced "anhedonia" in rats: pimozide blocks reward quality of food. Science 201:262-264

Wise RA, Spindler J, Legault L (1978b) Major attenuation of food reward with performance-sparing doses of pimozide in the rat. Can J Psychol 32:77-85

Wyvell CL, Berridge KC (2001) Incentive sensitization by previous amphetamine exposure: increased cue-triggered "wanting" for sucrose reward. J Neurosci 21:7831-7840

Xenakis S, Sclafani A (1982) The dopaminergic mediation of a sweet reward in normal and VMH hyperphagic rats. Pharmacol Biochem Behav 16:293-302

Young AM (2004) Increased extracellular dopamine in nucleus accumbens in response to unconditioned and conditioned aversive stimuli: studies using $1 \mathrm{~min}$ microdialysis in rats. J Neurosci Methods 138:57-63

Young AB, Penney JB (1993) Biochemical and functional organization of the basal ganglia. In: Jankowic J, Tolosa E (eds) Parkinson's disease and movement disorders. Williams and Wilkins, Baltimore, pp 1-12

Yu WZ, Silva RM, Sclafani A, Delamater AR, Bodnar RJ (2000) Pharmacology of flavor preference conditioning in sham-feeding rats: effects of dopamine receptor antagonists. Pharmacol Biochem Behav 65:635-647

Zahm DS (2000) An integrative neuroanatomical perspective on some subcortical substrates of adaptative responding with emphasis on the nucleus accumbens. Neurosci Biobehav Rev 24:85-105

Zahm DS, Brog JS (1992) On the significance of the subterritories in the "accumbens" part of the rat ventral striatum. Neuroscience 50:751-767

Zahm DS, Hemier L (1990) Two transpallidal pathways originating in rat nucleus accumbens. J Comp Neurol 302:437-446

Zigmond MJ, Acheson AL, Stowiak MK, Striker EM (1984) Neurochemical compensation after nigrostriatal bundle injury in an animal model of parkinsonism. Arch Neurol 41:856-861 